This document is the unedited Author's version of a Submitted Work that was subsequently accepted for publication in Colloids and Surfaces A: Physicochemical and Engineering Aspects, copyright $\mathbb{C}$ Elsevier after peer review. To access the final edited and published work see: http://dx.doi.org/10.1016/j.colsurfa.2017.02.065 


\title{
High-Performance Iron Oxide-Graphene Oxide Nanocomposite Adsorbents for Arsenic Removal
}

\author{
Hui Su, ${ }^{1}$ Zhibin $\mathrm{Ye}^{1, *}$ and Nuri Hmidi ${ }^{2}$ \\ 1 Bharti School of Engineering, Laurentian University, Sudbury, Ontario P3E 2C6, Canada \\ 2 Goldcorp Incorporated, Red Lake Gold Mines, 15 Mine Road, Box 2000, Balmertown, \\ Ontario P0V 1C0, Canada \\ * Corresponding author. Email: zye@laurentian.ca; Telephone: 1 (705) 6751151 ext. 2343
}




\begin{abstract}
We report the synthesis of a new range of iron oxide-graphene oxide (GO) nanocomposites having different iron oxide content (36-80 wt\%) as high-performance adsorbents for arsenic removal. Synthesized by co-precipitation of iron oxide on GO sheets that are prepared by an improved Hummers method, the iron oxide in the nanocomposites is featured primarily in the desirable form of amorphous nanoparticles with an average size of ca. $5 \mathrm{~nm}$. This unique amorphous nanoparticle morphology of the iron oxide beneficially endows the nanocomposites with high surface area (up to $341 \mathrm{~m}^{2} \mathrm{~g}^{-1}$ for $\mathrm{FeO}_{\mathrm{x}}-\mathrm{GO}-80$ having the iron oxide content of 80 $\mathrm{wt} \%$ ) and predominant mesopore structures, and consequently increased adsorption sites and enhanced arsenic adsorption capacity. $\mathrm{FeO}_{\mathrm{x}}-\mathrm{GO}-80$ shows high maximum arsenic adsorption capacity $\left(q_{\max }\right)$ of 147 and $113 \mathrm{mg} \mathrm{g}^{-1}$ for $\mathrm{As}(\mathrm{III})$ and $\mathrm{As}(\mathrm{V})$, respectively. These values are the highest among all the iron oxide-GO/reduced GO composite adsorbents reported to date and are also comparable to the best values achieved with various sophisticatedly synthesized iron oxide nanostructures. More strikingly, $\mathrm{FeO}_{\mathrm{x}}-\mathrm{GO}-80$ is also demonstrated to nearly completely (>99.98\%) removes arsenic by reducing the concentration from 118 (for As(III)) or 108 (for $\mathrm{As}(\mathrm{V}))$ to $<0.02 \mu \mathrm{g} \mathrm{L} \mathrm{L}^{-1}$, which is far below the limit of $10 \mu \mathrm{g} \mathrm{L}^{-1}$ recommended by the World Health Organization (WHO) for drinking water. The excellent adsorption performance, along with their low cost and convenient synthesis, makes this range of adsorbents highly promising for commercial applications in drinking water purification and wastewater treatment.
\end{abstract}

Keywords: graphene oxide, arsenic adsorption, iron oxide, nanocomposite, adsorbent. 


\section{Introduction}

Arsenic is one of the most toxic and carcinogenic chemical elements. Arsenic contamination of natural water sources due to mineral leaching and/or anthropogenic activities has been considered as one of the most serious environmental problems worldwide [1-3]. Inorganic arsenic species, primarily in the forms of arsenate $(\mathrm{As}(\mathrm{V}))$ and arsenite $(\mathrm{As}(\mathrm{III}))$, are believed to be more toxic than the organic forms. Both $\mathrm{As}(\mathrm{V})$ and $\mathrm{As}(\mathrm{III})$ exist in natural water, with the latter being more toxic and more difficult to remove than the former [1-3]. To date, a variety of techniques has been developed to remove arsenic from both natural and industrial water sources such as coagulation, adsorption, ion exchange, membrane filtration, biological remediation, etc. $[3,4]$ In particular, adsorption is considered to be most economical and efficient over other techniques, especially in the low concentration range. A wide range of adsorbents has been studied to remove arsenic from water and wastewater, including commercial activated carbons, metal oxides, soils and constituents, natural minerals, etc. $[3,4]$

Compared to other types of adsorbents, iron oxide-derived adsorbents have received enormous attention for arsenic removal due to their superior performance for arsenic adsorption [5]. In this regard, iron oxides in various forms have been studied and developed for arsenic removal, including amorphous iron oxide [6,7], goethite $(\alpha-\mathrm{FeOOH})[8]$, hematite $\left(\alpha-\mathrm{Fe}_{2} \mathrm{O}_{3}\right)[8,9]$, crystalline magnetic maghemite $\left(\gamma-\mathrm{Fe}_{2} \mathrm{O}_{3}\right)$ and magnetite $\left(\mathrm{Fe}_{3} \mathrm{O}_{4}\right)$ nanoparticles [10-12], as well as other iron oxide nanostructures [13-20]. Among them, amorphous iron oxides show the

highest adsorption capacity (as high as 260 and $200 \mathrm{mg} \mathrm{g}^{-1}$ for $\mathrm{As}(\mathrm{III})$ and $\mathrm{As}(\mathrm{V})$, respectively) due to its highest specific surface area [8], but with the shortcomings of its difficulty (as fine powders) for separation following adsorption and its tendency to form low-surface-area crystalline iron oxides during preparation [4]. On the contrary, magnetic crystalline iron oxides 
[10-12] and the various iron oxide nanostructures [13-20] generally show lowered adsorption capacity due to their low specific surface area.

Iron oxide-derived nanocomposite adsorbents prepared by loading iron oxides onto various substrates have also been extensively developed and investigated for arsenic adsorption $[3,4]$. Typical substrates include low-cost abundant ones, such as naturally occurring minerals [21], activated carbons [22], graphene oxide (GO) [23-33], and cellulose [34], as well as some specially synthesized costly ones, such as mesoporous carbons [35,36], carbon nanotubes [37], macroporous silica [38], etc. Such nanocomposite adsorbents facilitate their more convenient separation following adsorption. However, their maximum arsenic adsorption capacity is often relatively low, except in one case with specially designed, costly macroporous silica as the substrate [38]. Due to its unique two-dimensional one-atom-thick sheet structure with high surface area and abundant oxygen-containing functionalities, GO prepared easily from abundant graphite by oxidization and reduced GO (RGO) prepared by subsequent reduction of GO have recently received enormous interest for environmental remediation applications [39-42]. Crystalline magnetic iron oxide nanoparticles have been loaded onto GO or RGO, rendering nanocomposite adsorbents for arsenic adsorption [23,33]. However, the arsenic adsorption capacity achieved thus far with the iron oxide-GO/RGO nanocomposite adsorbents is commonly very low [only up to 54 and $73 \mathrm{mg} \mathrm{g}^{-1}$ reported for $\mathrm{As}(\mathrm{III})$ and $\mathrm{As}(\mathrm{V})$, respectively], with significant room for further improvements.

Tackling the above issues, we report in this paper the synthesis of a range of cost-effective amorphous iron oxide-GO nanocomposite adsorbents of significantly improved arsenic adsorption capacity. The key to the enhanced adsorption capacity is the unique loading of primarily amorphous iron oxide nanoparticles of high specific surface area on GO. The composite adsorbents have been designed to contain different contents of the amorphous iron 
oxide, and have been thoroughly characterized for their compositional, structural, and textural properties. A systematic study on the performance of these composite adsorbents for the adsorption of $\mathrm{As}(\mathrm{III})$ and $\mathrm{As}(\mathrm{V})$ has been undertaken. Our results suggest their high potential as cost-effective adsorbents for arsenic removal from both drinking water and industrial wastewater.

\section{Experimental Section}

\subsection{Materials}

Natural graphite flake (+100 mesh: $\geq 75.5 \%$, Aldrich), potassium permanganate $(99.0+\%$, Sigma Aldrich), hydrogen peroxide (50\%, Fisher Scientific), sulfuric acid (96.9 wt \%, Fisher Scientific), phosphoric acid (85+\%, Acros), ferrous sulfate heptahydrate (99+\%, Sigma Aldrich), ferric sulfate hydrate (97\%, Fe 21.6\%, Sigma Aldrich), ammonium hydroxide solution (28-30\%, Sigma Aldrich), hydrochloric acid (37\%, Fisher Scientific), methanol (ACS reagent, Fisher Scientific), were used as received without any additional purification. Deionized water was purified by a Barnstead/Synbron Nanopure II purification system.

Sodium (meta) arsenite $\left(\mathrm{NaAsO}_{2}, \geq 90 \%\right.$, Aldrich) and sodium arsenate dibasic heptahydrate $\left(\mathrm{Na}_{2} \mathrm{HAsO}_{4} \cdot 7 \mathrm{H}_{2} \mathrm{O}, \geq 98 \%\right.$, Aldrich) were selected as the source of $\mathrm{As}(\mathrm{III})$ and $\mathrm{As}(\mathrm{V})$, respectively. As(III) and $\mathrm{As}(\mathrm{V})$ stock solutions at the arsenic concentration of $2,000 \mathrm{mg} \mathrm{L}^{-1}$ were prepared in deionized water. The standard arsenic solutions with different concentrations were

diluted from the $2,000 \mathrm{mg} \mathrm{L}^{-1}$ stock solutions with the $\mathrm{pH}$ adjusted to desired values with $\mathrm{HNO}_{3}$ or $\mathrm{NaOH}$. 


\subsection{Synthesis of graphene oxide (GO)}

GO was synthesized by exfoliation of natural graphite flakes with the use of an improved Hummers method reported by Tour et al. [43] In a typical process, a mixture of concentrated $\mathrm{H}_{2} \mathrm{SO}_{4} / \mathrm{H}_{3} \mathrm{PO}_{4}(360: 40 \mathrm{~mL})$ was prepared in a round-bottom flask, then $3 \mathrm{~g}$ of graphite flakes were added to the mixture under vigorous mechanic stirring for $10 \mathrm{~min}$ to obtain a dark-colored suspension. Subsequently, $18 \mathrm{~g}$ of $\mathrm{KMnO}_{4}$ were added slowly into the above suspension in an ice bath. The mixture was stirred vigorously for $36 \mathrm{~h}$ at $50{ }^{\circ} \mathrm{C}$. A reddish brown viscous mixture was obtained. This mixture was cooled to room temperature, and then poured slowly into $400 \mathrm{~mL}$ of cold deionized water containing $3 \mathrm{~mL}$ of $\mathrm{H}_{2} \mathrm{O}_{2}$ (50\%). Afterwards, the suspension was centrifuged and washed sequentially with $\mathrm{HCl}$, water, then methanol for several times, until $\mathrm{pH}$ reached 6 . The solid material was collected after centrifugation and dispersed again in $1200 \mathrm{~mL}$ of water as the stock solution (GO concentration of $3.5 \mathrm{mg} \mathrm{mL}^{-1} ; 4.2 \mathrm{~g}$ in total) for subsequent use.

\subsection{Preparation of amorphous iron oxide-GO nanocomposites (FeO $\left.\mathrm{x}_{\mathrm{x}}-\mathrm{GOs}\right)$}

$\mathrm{FeO}_{\mathrm{x}}-\mathrm{GO}$ composites were synthesized by the co-precipitation method. The GO suspension (64 $\mathrm{mL}$, containing $0.22 \mathrm{~g}$ of $\mathrm{GO}$ ) was first diluted with $160 \mathrm{~mL}$ of water. An aqueous solution of $\mathrm{Fe}_{2}\left(\mathrm{SO}_{4}\right)_{3}$ and $\mathrm{FeSO}_{4}$ at 1:1 molar ratio (or $\mathrm{Fe}^{3+}: \mathrm{Fe}^{2+}=2: 1$ ) was prepared. In the case for the preparation of the nanocomposite with $80 \mathrm{wt} \%$ of iron oxide $\left(\mathrm{FeO}_{\mathrm{x}}-\mathrm{GO}-80\right)$, the amounts of ferric sulfate hydrate and ferrous sulfate heptahydrate were $1.51 \mathrm{~g}$ and $0.81 \mathrm{~g}$, respectively. The solutions of $\mathrm{Fe}_{2}\left(\mathrm{SO}_{4}\right)_{3}$ and $\mathrm{FeSO}_{4}$ were added into the $\mathrm{GO}$ suspension slowly at room temperature. Subsequently, 30\% ammonia solution was added under stirring to this suspension to make $\mathrm{pH}=10$. The suspension was heated to $85^{\circ} \mathrm{C}$ and was rapidly stirred for $40 \mathrm{~min}$. It was then cooled down to room temperature. The resulting black suspension was filtered, washed with 
water and methanol several times, and finally dried overnight under vacuum at $60{ }^{\circ} \mathrm{C}$, rendering $850 \mathrm{mg}$ of $\mathrm{FeO}_{\mathrm{x}}-\mathrm{GO}-80$. Two other nanocomposites $\left(\mathrm{FeO}_{\mathrm{x}}-\mathrm{GO}-36\right.$ and $\left.\mathrm{FeO}_{\mathrm{x}}-\mathrm{GO}-60\right)$ containing different contents (36 and $60 \mathrm{wt} \%$, respectively) of iron oxide were similarly prepared. The pure iron oxide control sample was synthesized with the same method, but in the absence of GO.

\subsection{Characterizations and Measurements}

Thermogravimetric analysis (TGA) of the $\mathrm{FeO}_{\mathrm{x}}-\mathrm{GO}$ nanocomposites was carried out on a $\mathrm{Q} 50$ TGA from TA instruments. Measurements were performed in an air atmosphere. In a typical measurement, the sample $(10 \mathrm{mg})$ was heated to $100{ }^{\circ} \mathrm{C}$ at a rate of $10^{\circ} \mathrm{C} \mathrm{min}^{-1}$, held at $100{ }^{\circ} \mathrm{C}$ for $10 \mathrm{~min}$, and then heated to $800{ }^{\circ} \mathrm{C}$ at a rate of $10{ }^{\circ} \mathrm{C} \mathrm{min}{ }^{-1}$. Braunauer-Emmett-Teller (BET) specific surface area, pore volume, and pore size distribution of the samples were determined by $\mathrm{N}_{2}$ sorption at $77 \mathrm{~K}$ using a Micromeritics ASAP 2020 physiosorption analyzer. Before the sorption measurements, the samples were degassed under vacuum at $100{ }^{\circ} \mathrm{C}$ for at least $12 \mathrm{~h}$. Xray photoelectron spectroscopy (XPS) measurements of $\mathrm{FeO}_{\mathrm{x}}-\mathrm{GO}$ nanocomposites were carried out on a Thermo Scientific Theta Probe XPS spectrometer. A monochromatic Al Ka X-ray source was used, with a spot area of $400 \mu \mathrm{m}$. The samples were run in a standard mode, i.e., all angles collected $\left(60^{\circ}\right.$ angular acceptance) for the survey spectra, and for the region spectra. Wide-angle $\mathrm{x}$-ray diffraction (XRD) patterns of the $\mathrm{FeO}_{\mathrm{x}}-\mathrm{GO}$ nanocomposites were recorded on an X'Pert Pro diffractometer with $\mathrm{Cu}$ radiation (wavelength $1.54 \AA$ ) at room temperature. Transmission electron microscopy (TEM) images were taken on a JEOL 2010F field emission electron microscope operated at $200 \mathrm{keV}$. The TEM samples were prepared by depositing a few

drops of a dilute dispersion of the $\mathrm{FeO}_{\mathrm{x}}-\mathrm{GO}$ composites in methanol on holey grids, followed with drying. Atomic force microscopy (AFM) imaging of the GO sample was performed on a Bruker multimode atomic force microscope in the tapping mode with a phosphorous-doped silicon tip having a force constant of $20-80 \mathrm{~N} \mathrm{~m}^{-1}$. AFM samples were prepared by placing a 
freshly cleaved mica piece in the dilute dispersion (ca. $0.1 \mathrm{mg} \mathrm{mL}^{-1}$ ) of the GO sample overnight for sample deposition, which was then taken out and dried for the imaging. Fourier-transformed infrared (FTIR) spectra were obtained on a Thermo Scientific Nicolet 6700 Analytical FTIR spectrometer. The samples were prepared as pellets using spectroscopic-grade KBr. Zeta potential measurements of the dilute dispersions $\left(0.1 \mathrm{mg} \mathrm{mL} \mathrm{mL}^{-1}\right)$ of the various $\mathrm{FeO}_{\mathrm{x}}-\mathrm{GO}$ composites were performed with a Brookhaven NanoBrook Omni Instrument at $25{ }^{\circ} \mathrm{C}$. The concentration of arsenic was measured with an Analytik Jena 810 inductively coupled plasmon mass spectrometry (ICP-MS) system with a detection limit of $50 \mu \mathrm{g} \mathrm{L}^{-1}$ or with a Thermal Fisher iCAP Q ICP-MS system with a detection limit of $0.02 \mu \mathrm{g} \mathrm{L}^{-1}$ for the solutions with arsenic in the very low concentration range. Raman spectra (excitation at $514 \mathrm{~nm}$ ) were recorded on a Reinshaw Invia Laser Raman spectrometer.

\subsection{Arsenic Adsorption}

All the arsenic adsorption experiments were undertaken at room temperature, i.e., $23{ }^{\circ} \mathrm{C}$, which is most common for arsenic adsorption studies. Batch equilibrium adsorption of arsenic was carried out at an adsorbent loading of $0.8 \mathrm{mg} \mathrm{mL}^{-1}$. Typically, the $\mathrm{FeO}_{\mathrm{x}}-\mathrm{GO}$ composites $(2.4 \mathrm{mg})$ were dispersed in the $\mathrm{As}(\mathrm{III})$ and $\mathrm{As}(\mathrm{V})$ solutions $(3 \mathrm{~mL})$ at different initial concentrations (0.1-1200 $\left.\mathrm{mg} \mathrm{L}^{-1}\right)$ and $\mathrm{pH}$, followed by magnetic stirring $(300 \mathrm{rpm})$ for $24 \mathrm{~h}$ to achieve adsorption equilibrium. Afterwards, the suspension was filtered with a $0.2 \mu \mathrm{m}$ Teflon syringe filter and the equilibrium concentration of non-adsorbed arsenic in the filtrate solution was measured. The equilibrium adsorption uptake $\left(q_{e}\right.$ in $\left.\mathrm{mg} \mathrm{g}^{-1}\right)$ was calculated according to Equation 1 from the difference between the initial arsenic concentration $\left(C_{0}, \mathrm{mg} \mathrm{L}^{-1}\right)$ and the equilibrium one $\left(C_{e}, \mathrm{mg}\right.$ $\left.\mathrm{L}^{-1}\right)$ :

$$
q_{e}=\left(C_{0}-C_{e}\right) V / m
$$

where $V$ is the solution volume (L), and $m$ is the mass of the adsorbent $(\mathrm{g})$. 
The adsorption isotherms were fitted with the Langmuir model (Equation 2).

$$
q_{e}=a b C_{e} /\left(1+b C_{e}\right)
$$

where $a$ is the saturated/maximum adsorbed capacity $\left(\mathrm{mg} \mathrm{g}^{-1}\right)$ and $b$ is the Langmuir constant that directly relates to the adsorption affinity $\left(\mathrm{L} \mathrm{mg}^{-1}\right)$.

The adsorption kinetic curves with $\mathrm{FeO}_{\mathrm{x}}-\mathrm{GO}-80$ were obtained as follows. $\mathrm{FeO}_{\mathrm{x}}-\mathrm{GO}-80$ at the same amount $(2.4 \mathrm{mg})$ was dispersed in a series of $\mathrm{As}(\mathrm{III})$ and $\mathrm{As}(\mathrm{V})$ standard solutions of the same volume $(3 \mathrm{~mL})$ and concentration $\left[400 \mathrm{mg} \mathrm{L}^{-1}\right.$ for $\mathrm{As}(\mathrm{III})$ and $350 \mathrm{mg} \mathrm{L}^{-1}$ for $\left.\mathrm{As}(\mathrm{V})\right]$. Each dispersion was stirred for a prescribed time (ranging from $15 \mathrm{~min}$ to $24 \mathrm{~h}$ ) and was then quickly filtered for measurement of the corresponding equilibrium concentration of $\mathrm{As}(\mathrm{III})$ and $\mathrm{As}(\mathrm{V})$ in the filtrate, thus giving rise to the time-dependent adsorption capacity. The adsorption kinetics was fitted with the pseudo-second-order kinetic model (Equation 3 or 4 ) based on which the initial adsorption rate could be obtained (Equation 5).

$$
\begin{aligned}
& \mathrm{d} q_{t} / \mathrm{d} t=k_{2}\left(q_{e}-q_{t}\right)^{2} \\
& t / q_{t}=1 /\left(k_{2} q_{e}^{2}\right)+t / q_{e} \\
& V_{0}=k_{2} q_{e}{ }^{2}
\end{aligned}
$$

where $q_{t}$ is the amount $\left(\mathrm{mg} \mathrm{g}^{-1}\right)$ of arsenic adsorbed on adsorbent at various time $t, k_{2}$ is the rate constant $\left(\mathrm{g} \mathrm{mg}^{-1} \mathrm{~min}^{-1}\right), q_{e}$ is the equilibrium adsorption capacity $\left(\mathrm{mg} \mathrm{g}^{-1}\right)$, and $V_{0}$ is the initial adsorption rate $\left(\mathrm{mg} \mathrm{g}^{-1} \mathrm{~min}^{-1}\right)$.

The effects of coexisting anions $\left(\mathrm{CO}_{3}{ }^{2-}, \mathrm{SO}_{4}{ }^{2-}\right.$, and $\left.\mathrm{PO}_{4}{ }^{3-}\right)$ on the batch adsorption of As(III) and $\mathrm{As}(\mathrm{V})$ were investigated with $\mathrm{FeO}_{\mathrm{x}}-\mathrm{GO}-80$ at the initial arsenic concentration of around $100 \mu \mathrm{g}$ $\mathrm{L}^{-1}$ at the $\mathrm{pH}$ of 6.5 . The molar concentration of the coexisting anions was set excessively at 1,000 times of that of arsenic (i.e., 184, 189, and $282 \mathrm{mg} \mathrm{L}^{-1}$ for $\mathrm{K}_{2} \mathrm{CO}_{3}, \mathrm{Na}_{2} \mathrm{SO}_{4}$, and $\mathrm{K}_{3} \mathrm{PO}_{4}$ respectively), with the adsorbent loading of $5 \mathrm{mg}$ in $6.25 \mathrm{~mL}$ (i.e., $0.8 \mathrm{mg} \mathrm{mL}^{-1}$ ). Each adsorption 
underwent for $24 \mathrm{~h}$ under stirring. Afterwards, the suspension was filtered and the filtrate was analyzed with ICP-MS for equilibrium arsenic concentration and the subsequent calculation of the equilibrium adsorption capacity by Equation 1.

\section{Results and Discussion}

\subsection{Synthesis and Characterization of $\mathrm{FeO}_{\mathrm{x}}$-GOs Nanocomposites}

The Hummers method [44] or modified Hummers method has been commonly used for the preparation of $\mathrm{GO}$ in the previous studies on iron oxide-GO/RGO composite adsorbents for arsenic adsorption [23-33]. Unlike those previous studies, GO used herein was synthesized with an improved Hummers method developed by Tour et al. [43] Relative to the Hummers and modified Hummers methods, the improved method is noted for improved oxidation efficiency and the greater retention of the graphitic basal plane framework. Figure S1 in Supporting Information shows an AFM image of the GO sample synthesized and employed herein. It consists of typical 2-dimensional sheet-like structures, which are loosely bound. The sheets have the lateral dimension within the range of ca. 1-10 $\mu \mathrm{m}$ and the thickness of around 1-2 nm (see Figure S1). The GO sample was characterized with XPS. Its $\mathrm{C}_{1 \mathrm{~s}}$ XPS spectrum (see Figure $\mathrm{S} 2$ ) is

deconvoluted into four peaks that correspond to the following functional groups: carbon $\mathrm{sp}^{2}$ $(\mathrm{C}=\mathrm{C}, 284.8 \mathrm{eV})$, epoxy/hydroxyls $(\mathrm{C}-\mathrm{O}, 287.0 \mathrm{eV})$, carbonyl $(\mathrm{C}=\mathrm{O}, 288.8 \mathrm{eV})$, and carboxylates $(\mathrm{O}-\mathrm{C}=\mathrm{CO}, 289.9 \mathrm{eV})$ [45]. Integration of the deconvoluted peaks indicates that the GO sample has $64 \%$ oxidized carbon and $36 \%$ graphitic carbon. This indicates a very high degree of functionalization, where the edges and basal plane of each sheet should be functionalized with oxygen-containing polar groups, such as carboxyl, epoxy, hydroxyl, etc. 
Due to the high degree of functionalization, the GO powder readily disperses in water to form a stable aqueous suspension upon ultrasonication and stirring. To prepare $\mathrm{FeO}_{\mathrm{x}}-\mathrm{GO}$ composites, iron salts, $\mathrm{Fe}_{2}\left(\mathrm{SO}_{4}\right)_{3}$ and $\mathrm{FeSO}_{4}$ at 1:1 molar ratio, were added into the aqueous $\mathrm{GO}$ suspension as the iron oxide precursors. Iron compounds have been reported to form cross-linking with the oxygen functionalities on the surface of carbon materials [45]. Subsequently, ammonium hydroxide was added into the mixture, followed with subsequent reaction at $85{ }^{\circ} \mathrm{C}$ and posttreatment (precipitation, washing, and drying at $60^{\circ} \mathrm{C}$ ). With the equal molar feeding of the two iron salts, we expected to obtain iron oxide with $\mathrm{Fe}^{3+}$ and $\mathrm{Fe}^{2+}$ at a molar ratio of 2 in the composites. Scheme 1 shows the schematic synthesis. By controlling the feed ratio of the iron salts to $\mathrm{GO}$, three $\mathrm{FeO}_{\mathrm{x}}-\mathrm{GO}$ composites having different iron oxide contents were prepared. Meanwhile, a pure iron oxide control sample was also synthesized in the absence of GO for the purpose of comparison.
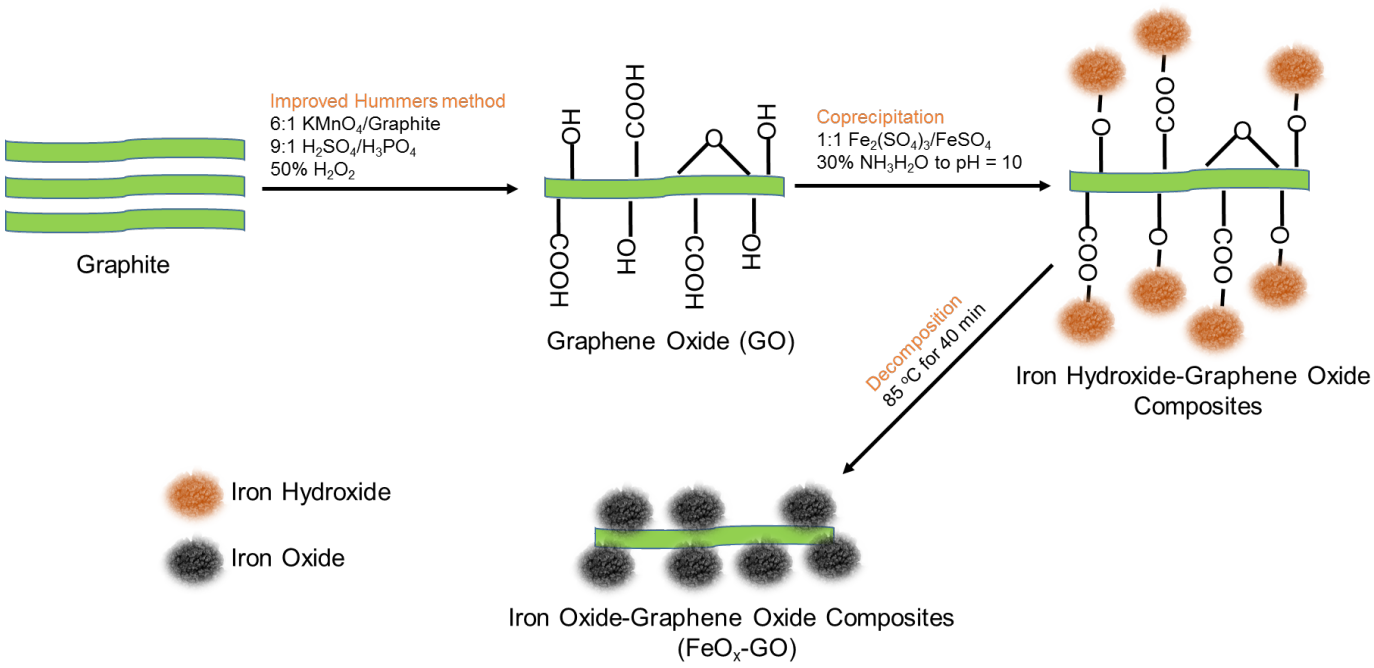

Scheme 1. Schematic synthesis of $\mathrm{FeO}_{\mathrm{x}}-\mathrm{GO}$ nanocomposites.

The resulting composites were thoroughly characterized. Figure 1 shows the TGA curves of the composites and their differential curves, along with those of GO and the iron oxide control sample. GO shows a characteristic two-step weight loss. The first step (loss of ca. 40\%) occurs 
within $150-250^{\circ} \mathrm{C}$ with the peak weight loss at $203^{\circ} \mathrm{C}$. It can be attributed to the evaporation of adsorbed water and the decomposition of thermally labile oxygen-containing functional groups. The second weight loss takes place within $400-500{ }^{\circ} \mathrm{C}$ (peak at $467{ }^{\circ} \mathrm{C}$ ) with negligible char yield at $600{ }^{\circ} \mathrm{C}$. It is ascribed to the decomposition of more stable oxygen functionalities and the combustion of GO framework [46]. On the contrary, the iron oxide control sample shows negligible weight loss even at $600^{\circ} \mathrm{C}$. The $\mathrm{FeO}_{\mathrm{x}}-\mathrm{GO}$ composites show weight loss within $100-$ $420{ }^{\circ} \mathrm{C}$. Their char yield at $600{ }^{\circ} \mathrm{C}$, which represents the content of iron oxide in the nanocomposites, is 36,60 , and $80 \mathrm{wt} \%$, respectively. In consequence, the composites are termed correspondingly as $\mathrm{FeO}_{\mathrm{x}}-\mathrm{GO}-36, \mathrm{FeO}_{\mathrm{x}}-\mathrm{GO}-60$, and $\mathrm{FeO}_{\mathrm{x}}-\mathrm{GO}-80$, with the number representing the mass percentage of iron oxide in the composites. In particular, the iron oxide content in $\mathrm{FeO}_{\mathrm{x}}-\mathrm{GO}-80$ is significantly higher than the typical values (around 10-60 wt\%) in iron oxideGO composites synthesized in earlier works for arsenic adsorption [23-33]. On the basis of their differential curves, the major weight loss of the composites occurs within $250-500{ }^{\circ} \mathrm{C}$, along with a long tail/shoulder peak within $100-250{ }^{\circ} \mathrm{C}$. This indicates the significant overlap of the two weight-loss steps due to the decrease of combustion/degradation temperature. With the increase of the iron oxide content, the peak weight-loss temperature shows a continuous decrease from $360{ }^{\circ} \mathrm{C}$ for $\mathrm{FeO}_{\mathrm{x}}-\mathrm{GO}-36$ to $338{ }^{\circ} \mathrm{C}$ for $\mathrm{FeO}_{\mathrm{x}}-\mathrm{GO}-60$ and to $318{ }^{\circ} \mathrm{C}$ for $\mathrm{FeO}_{\mathrm{x}}-\mathrm{GO}-80$. This can be ascribed to the enhanced surface area and pore volume with the increase of iron oxide content in the composites as shown below, which lead to the enhanced contact of GO surface with air for combustion. Meanwhile, it can also result from the existence of iron oxide on the GO surface, which acts as catalysts for the carbon combustion since their exothermic oxidation takes place at lower temperatures [36]. 

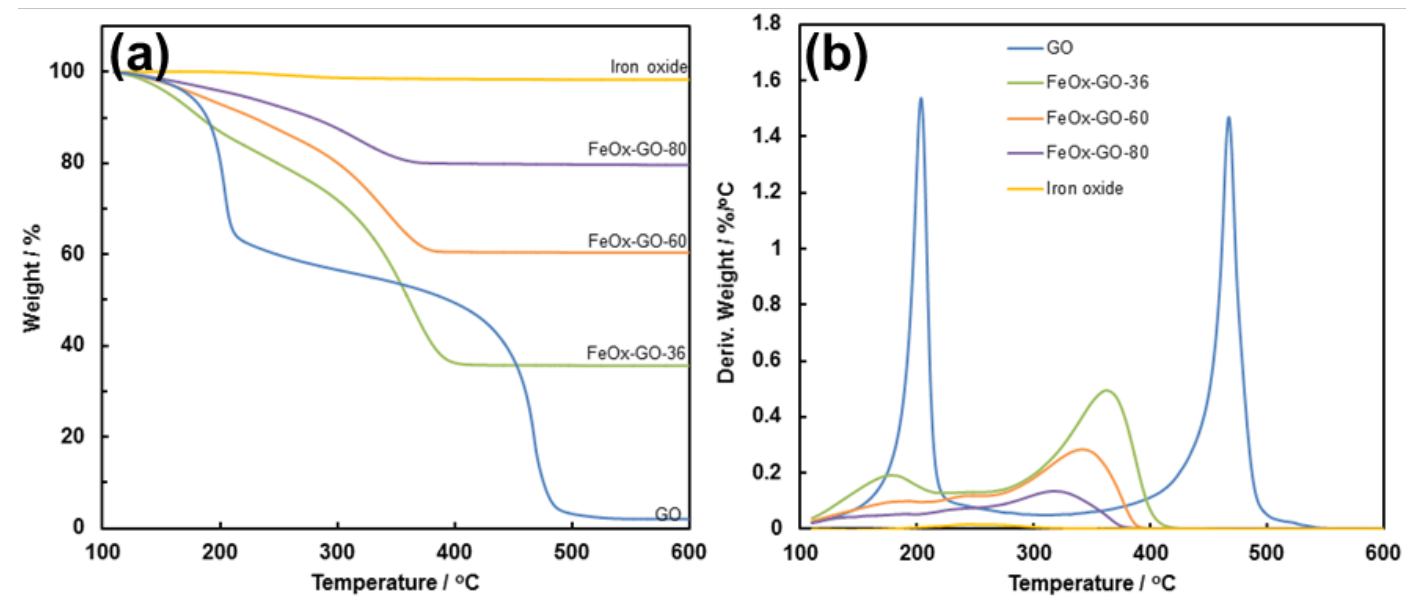

Figure 1. TGA curves (a) and differential curves (b) for $\mathrm{GO}, \mathrm{FeO}_{\mathrm{x}}-\mathrm{GO}-36, \mathrm{FeO}_{\mathrm{x}}-\mathrm{GO}-60, \mathrm{FeO}_{\mathrm{x}}-$ GO-80 and the iron oxide control sample in the air atmosphere.

Figure 2 shows the TEM images and high-resolution TEM images of two composites, $\mathrm{FeO}_{\mathrm{x}}-\mathrm{GO}-$ 36 and $\mathrm{FeO}_{\mathrm{x}}-\mathrm{GO}-80$, as well as those of $\mathrm{GO}$ and the iron oxide control sample. GO appears as wrinkled sheets under TEM (Figure 2(a)). The iron oxide control sample consists of nanoparticles with sizes in the range of 10-20 nm (Figure 2(g)). Figure S3 shows the particle size distribution on the basis of 120 nanoparticles examined under TEM, with the average size of $15 \mathrm{~nm}$. The atomic lattice fringes in the high-resolution TEM images (Figure 2(h)) confirm the single crystalline nature of the nanoparticles with an interplanar spacing of about $0.25 \mathrm{~nm}$, which matches well with the (311) lattice spacing of crystalline $\mathrm{Fe}_{3} \mathrm{O}_{4}$ [47]. In the two composites, GO sheets are decorated irregularly with iron oxide nanoparticles (see Figure 2(c) and (e)). From the high-resolution images (Figure 2(d) and (f)), the iron oxide nanoparticles have an average size of about $5 \mathrm{~nm}$ and are primarily amorphous with no distinct crystalline lattice fringes observed. This is in sharp contrast to the crystalline $\mathrm{Fe}_{3} \mathrm{O}_{4}$ nanoparticles observed in the iron oxide control sample, which was prepared under the same conditions except in the absence of GO. Clearly, the presence of $\mathrm{GO}$ in the coprecipitation preparation of iron oxide promotes the formation of amorphous iron oxide nanoparticles in the composites. 


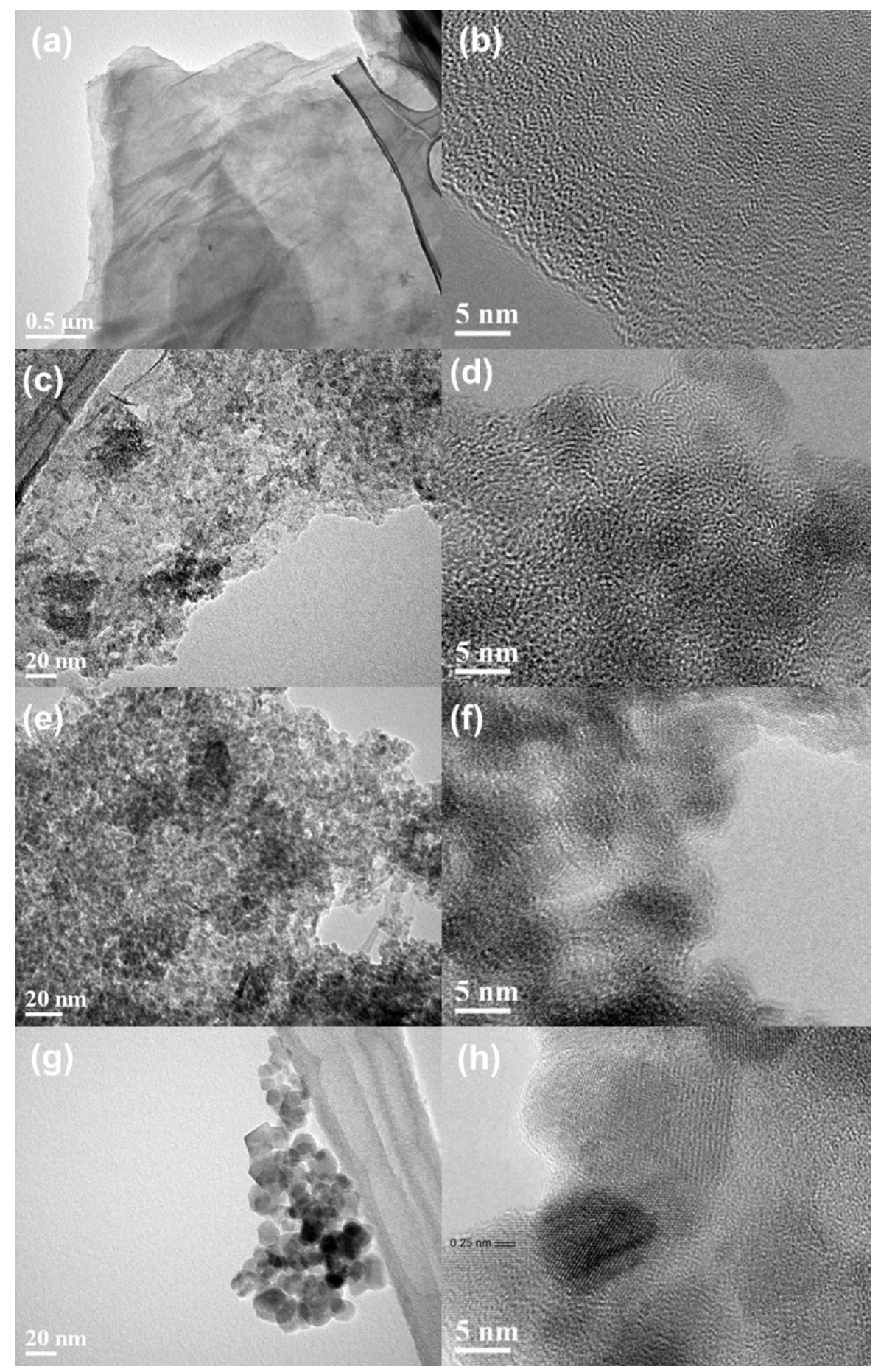

Figure 2. TEM and high-resolution TEM images of GO (a and b), $\mathrm{FeO}_{\mathrm{x}}-\mathrm{GO}-36$ (c and d), $\mathrm{FeO}_{\mathrm{x}}-\mathrm{GO}-80$ (e and $\mathrm{f}$ ), and the iron oxide control sample ( $\mathrm{g}$ and $\mathrm{h}$ ). 
To further elucidate the distribution of iron oxide species in the composites, the two composites $\left(\mathrm{FeO}_{\mathrm{x}}-\mathrm{GO}-36\right.$ and $\left.\mathrm{FeO}_{\mathrm{x}}-\mathrm{GO}-80\right)$ were characterized with the dark-field scanning TEM (DFSTEM) technique. As shown in Figure S4(a), bright spots can be found in the dark domain of $\mathrm{FeO}_{\mathrm{x}}-\mathrm{GO}-80$ containing $\mathrm{C}$ and $\mathrm{O}$, indicating the existence of heavy atoms, namely Fe. Figure S4(b)-(d) show the elemental mapping of $\mathrm{C}, \mathrm{O}$, and Fe within the domain. All the three elements are uniformly distributed, confirming the uniform dispersion of iron oxide within the composite. Similarly, the uniform distribution of iron oxide is also confirmed in $\mathrm{FeO}_{\mathrm{x}}-\mathrm{GO}-36$ having a lower iron oxide content (see Figure S5).

FTIR spectra of $\mathrm{GO}$, the $\mathrm{FeO}_{\mathrm{x}}-\mathrm{GO}$ composites, and the iron oxide control sample are shown in Figure 3. The spectrum of $\mathrm{GO}$ shows $\mathrm{C}=\mathrm{O}\left(1729 \mathrm{~cm}^{-1}\right)$, aromatic $\mathrm{C}=\mathrm{C}\left(1620 \mathrm{~cm}^{-1}\right)$, carboxyl $\mathrm{O}=\mathrm{C}-\mathrm{O}\left(1400 \mathrm{~cm}^{-1}\right)$, epoxy $\mathrm{C}-\mathrm{O}\left(1225 \mathrm{~cm}^{-1}\right)$, and alkoxy $\mathrm{C}-\mathrm{O}\left(1053 \mathrm{~cm}^{-1}\right)$ stretching vibrations [48]. The spectrum of iron oxide sample shows two broad bands in the low frequency region (750-400 $\mathrm{cm}^{-1}$ ), corresponding to the $\mathrm{Fe}-\mathrm{O}$ vibration in $\mathrm{Fe}_{3} \mathrm{O}_{4}$ [36]. The infrared spectra of $\mathrm{FeO}_{\mathrm{x}}-\mathrm{GO}-36, \mathrm{FeO}_{\mathrm{x}}-\mathrm{GO}-60$, and $\mathrm{FeO}_{\mathrm{x}}-\mathrm{GO}-80$ all show a broad band with the peak maximum at $1578 \mathrm{~cm}^{-1}$, corresponding to aromatic $\mathrm{C}=\mathrm{C}$ stretch in $\mathrm{GO}$ [23]. Other bands arising from GO become indistinct in the composites due to its lowered content. In $\mathrm{FeO}_{\mathrm{x}}-\mathrm{GO}-80$, the presence of iron oxide can be confirmed from the bands at $552 \mathrm{~cm}^{-1}$ and $442 \mathrm{~cm}^{-1} . \mathrm{FeO}_{\mathrm{x}^{-}} \mathrm{GO}-36$ and $\mathrm{FeO}_{\mathrm{x}^{-}}$ GO-60 show also similar spectral characteristics with more or less differences in the absorption intensities in the low wavenumber range due to their relatively lowered iron oxide content. 


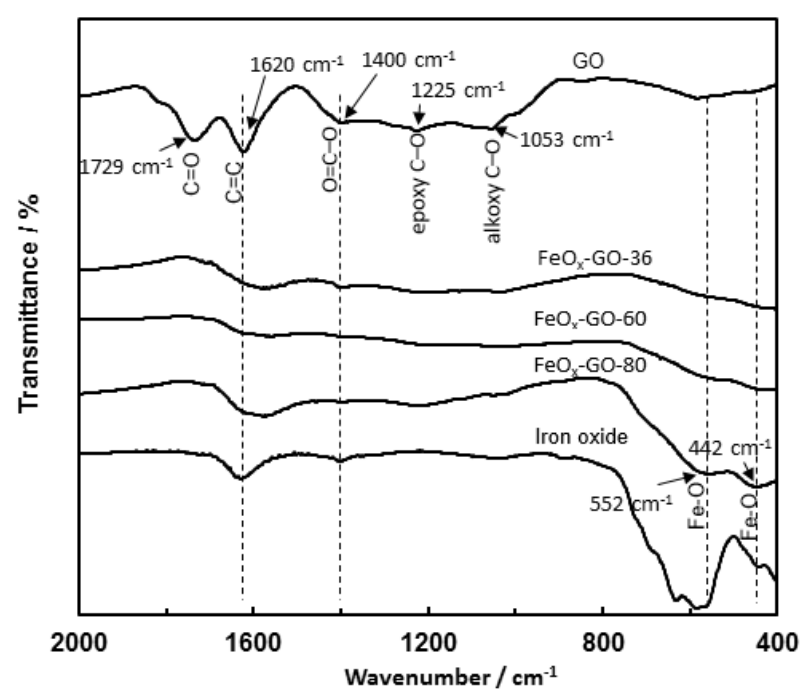

Figure 3. FTIR spectra of $\mathrm{GO}, \mathrm{FeO}_{\mathrm{x}}-\mathrm{GO}$ composites, and the iron oxide control sample.

Two composites, $\mathrm{FeO}_{\mathrm{x}}-\mathrm{GO}-36$ and $\mathrm{FeO}_{\mathrm{x}}-\mathrm{GO}-80$, as well as $\mathrm{GO}$ and the iron oxide control sample, were also characterized with XPS (see Figure 4). From the survey scan (Figure 4(a)), the surface of GO contains 40.4 atom $\%$ of $\mathrm{C}$ and 55.0 atom $\%$ of $\mathrm{O}$ (see Figure 4(b)). Impurities at small amounts are noticed in the samples on the basis of the peaks found in the higher energy region of the XPS spectra. After loading the amorphous iron oxide at the increasing content, the counts of $\mathrm{O}_{1 \mathrm{~s}}$ and $\mathrm{C}_{1 \mathrm{~s}}$ in the composites decrease (34.5 atom\% of $\mathrm{C}$ and 36 atom $\%$ of $\mathrm{O}$ for $\mathrm{FeO}_{\mathrm{x}^{-}}$ GO-36, 13.1 atom\% of $\mathrm{C}$ and 27.7 atom\% of $\mathrm{O}$ for $\mathrm{FeO}_{\mathrm{x}}-\mathrm{GO}-80$ ) whereas the counts of $\mathrm{Fe}$ increase dramatically (25.2 and 57.7 atom\% for $\mathrm{FeO}_{\mathrm{x}}-\mathrm{GO}-36$ and $\mathrm{FeO}_{\mathrm{x}}-\mathrm{GO}-80$, respectively). Two photoelectron peaks located at $711.1\left(\mathrm{Fe}_{2 \mathrm{p} 3 / 2}\right)$ and $724.6 \mathrm{eV}\left(\mathrm{Fe}_{2 \mathrm{p} 1 / 2}\right)$ are found in the $\mathrm{Fe}_{2 \mathrm{p}}$ spectra of the composites and the iron oxide control sample (Figure 4(c)-(e)) [23]. Each peak is deconvoluted to the constituting peaks attributable to $\mathrm{Fe}^{3+}$ and $\mathrm{Fe}^{2+}$, respectively, as well as their satellite peaks $[49,50]$. The $\mathrm{Fe}^{3+} / \mathrm{Fe}^{2+}$ molar ratio in the iron oxide control sample is estimated to 2.03 according to the deconvoluted $\mathrm{Fe}_{2 \mathrm{p} 3 / 2}$ peaks, which is nearly identical to the theoretical value of 2 for $\mathrm{Fe}_{3} \mathrm{O}_{4}$. This also confirms that the pure iron oxide control sample is in the form of $\mathrm{Fe}_{3} \mathrm{O}_{4}$ nanoparticles. The $\mathrm{Fe}^{3+} / \mathrm{Fe}^{2+}$ molar ratio in $\mathrm{FeO}_{\mathrm{x}}-\mathrm{GO}-36$ and $\mathrm{FeO}_{\mathrm{x}}-\mathrm{GO}-80$ is estimated to 
be 2.92 and 1.87, respectively. While the latter for $\mathrm{FeO}_{\mathrm{x}}-\mathrm{GO}-80$ is close to the expected theoretical value for $\mathrm{Fe}_{3} \mathrm{O}_{4}$, the former for $\mathrm{FeO}_{\mathrm{x}}-\mathrm{GO}-36$ at a lower iron oxide loading deviates significantly from the theoretical value. This may result from the stronger complexation of $\mathrm{Fe}^{3+}$ than $\mathrm{Fe}^{2+}$ ions with oxygen functionalities on GO during the preparation and thus the higher incorporation within the composite [24].
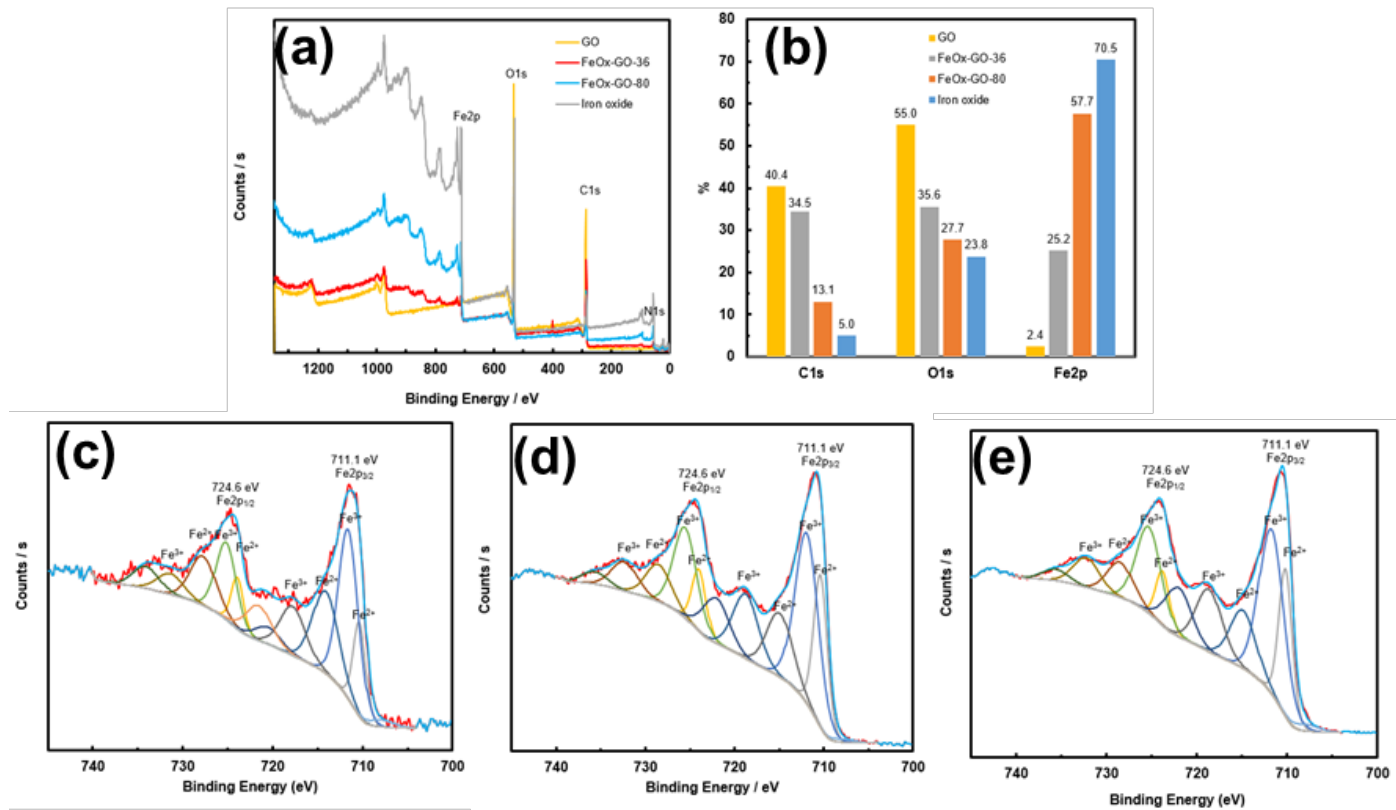

Figure 4. (a) XPS survey scan of $\mathrm{GO}, \mathrm{FeO}_{\mathrm{x}}-\mathrm{GO}-36, \mathrm{FeO}_{\mathrm{x}}-\mathrm{GO}-80$, and the iron oxide control sample, (b) the content of $\mathrm{C}, \mathrm{O}$, and Fe in the samples measured by XPS, (c)-(e) $\mathrm{Fe}_{2 p}$ spectra in $\mathrm{FeO}_{\mathrm{x}}-\mathrm{GO}-36, \mathrm{FeO}_{\mathrm{x}}-\mathrm{GO}-80$, and the iron oxide control sample, respectively.

The $\mathrm{O}_{1 \mathrm{~s}}$ spectra of the samples are shown in Figure $\mathrm{S} 2(\mathrm{~b})$. In the spectra of the two composites, three deconvoluted peaks at 530.3, 531.6, and $533.6 \mathrm{eV}$ are attributed to the oxygen atoms bonded to $\mathrm{O}-\mathrm{Fe}$, carboxyl $\mathrm{O}=\mathrm{C}$, and hydroxyl $\mathrm{O}-\mathrm{H}$, respectively [23]. In the spectrum of pure iron oxide, the former one is predominant with the negligible presence of the latter two. On the contrary, the former one is absent in GO. In the $\mathrm{C}_{1 \mathrm{~s}}$ spectra (Figure S2(a)), three deconvoluted peaks at $284.8,286.9$, and $288.8 \mathrm{eV}$, can be found in the composites, assignable to the $\mathrm{C}$ atoms 
in $\mathrm{C}-\mathrm{C}, \mathrm{C}-\mathrm{O}$, and $\mathrm{C}=\mathrm{O}$ groups in $\mathrm{GO}$. By comparing the deconvoluted peaks, it appears that, after loading iron oxide onto $\mathrm{GO}$, the relative intensity of the peak for $\mathrm{C}-\mathrm{O}$ bonds has been significantly reduced while with the increasing intensity of that for $\mathrm{C}-\mathrm{C}$ bonds, suggesting the partial conversion of GO to chemically converted graphene (CCG) [51]. Such a conversion may result from the partial reduction of $\mathrm{GO}$ by $\mathrm{Fe}^{2+}$ in the composites. This may also contribute to the above noted deviation of $\mathrm{Fe}^{3+} / \mathrm{Fe}^{2+}$ ratio from the expected theoretical value of 2 in the composites.

Figure 5 shows the XRD spectra of $\mathrm{GO}, \mathrm{FeO}_{\mathrm{x}}-\mathrm{GO}-36, \mathrm{FeO}_{\mathrm{x}}-\mathrm{GO}-80$, and the iron oxide control sample. In the spectrum of $\mathrm{GO}$, there is a strong peak at $12^{\circ}$ arising from the interlayer spacing between stacked GO sheets [43]. This peak is absent in both $\mathrm{FeO}_{\mathrm{x}}-\mathrm{GO}-36$ and $\mathrm{FeO}_{\mathrm{x}}-\mathrm{GO}-80$ due to the complete exfoliation of GO sheets by iron oxide. In addition, a very weak and broad peak is also noticed near $43^{\circ}$ (indicated by arrows) in the spectrum of GO, which is attributed to the (100) peak of graphitic structures [52]. The iron oxide control sample shows sharp strong diffraction peaks matching well those of $\mathrm{Fe}_{3} \mathrm{O}_{4}$ (JCPDS Card \#75-0033) or $\gamma$ - $\mathrm{Fe}_{2} \mathrm{O}_{3}$ (JCPDS Card \#39-1346), which have similar XRD patterns. But with the above XPS evidence, we can confirm that the iron oxide control sample is indeed in the form of crystalline $\mathrm{Fe}_{3} \mathrm{O}_{4}$. The average crystallite size $(L)$ is evaluated from the full width at half maximum of the (311) peak at $2 \theta=$ $35.5^{\circ}$ according to the Scherrer equation:

$$
L=\frac{K \lambda}{\beta \cos \theta}
$$

where $K$ is the shape factor usually assigned as $0.9, \lambda$ is the wavelength used $(1.54 \AA)$, and $\beta$ is the full width at half-maximum (in rad) of the diffraction peak. The resulting $L$ is $16.4 \mathrm{~nm}$, in good agreement with the average crystalline nanoparticle size of $15 \mathrm{~nm}$ found above from the TEM image (Figure 2(g)). Despite its high content of iron oxide, $\mathrm{FeO}_{\mathrm{x}}-\mathrm{GO}-80$ instead shows only some very weak diffraction peaks, which match the diffraction pattern of $\alpha-\mathrm{Fe}_{2} \mathrm{O}_{3}$ (JCPDS Card \#80-2377). In agreement with its TEM images, this indicates that the iron oxide in the 
composites is primarily in the amorphous form without a significant presence of crystalline nanoparticles. Like $\mathrm{FeO}_{\mathrm{x}}-\mathrm{GO}-80, \mathrm{FeO}_{\mathrm{x}}-\mathrm{GO}-36$ also shows weak (104) and (110) diffraction peaks characteristic of $\alpha-\mathrm{Fe}_{2} \mathrm{O}_{3}$; but other peaks are not clearly observable due to the low iron oxide content. Due to the primarily amorphous nature of the iron oxide, the three $\mathrm{FeO}_{\mathrm{x}}-\mathrm{GO}$ composites synthesized herein were found only weakly magnetic.

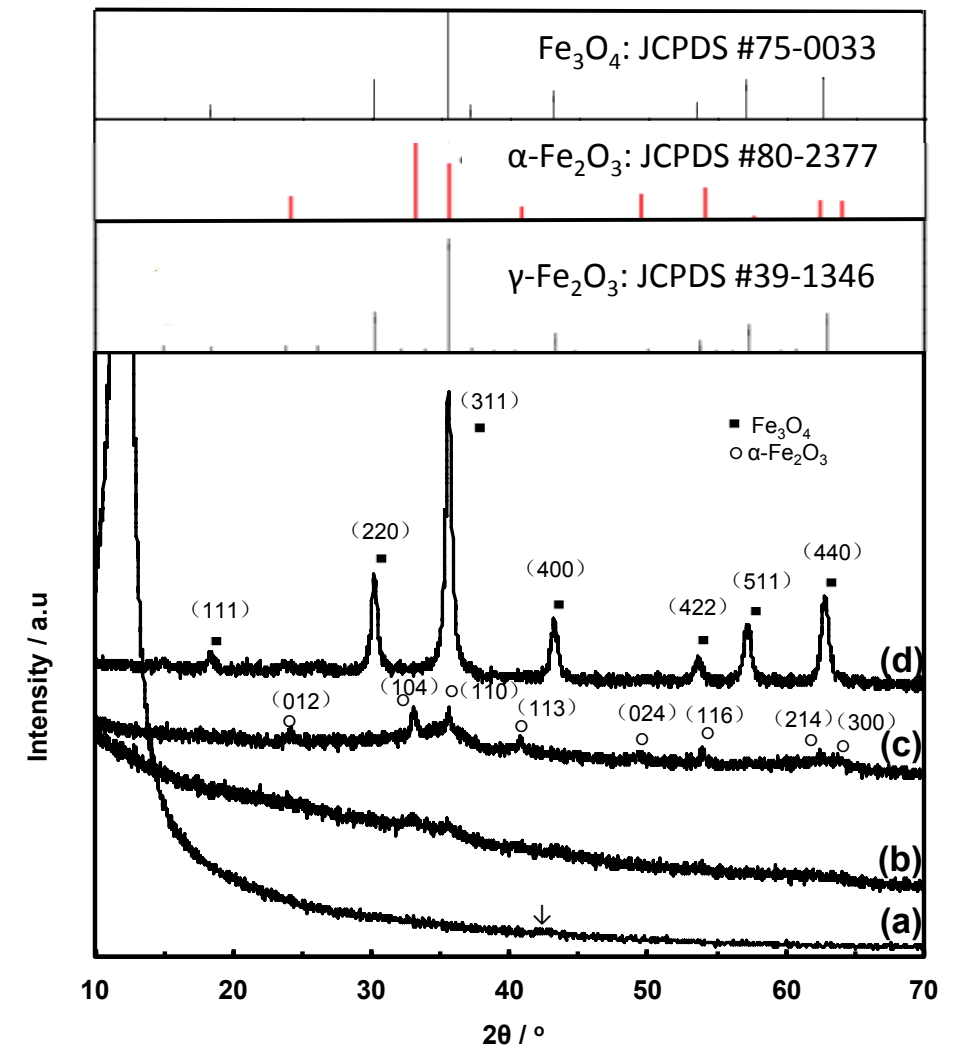

Figure 5. Wide-angle XRD patterns of (a) GO, (b) $\mathrm{FeO}_{\mathrm{x}}-\mathrm{GO}-36$, (c) $\mathrm{FeO}_{\mathrm{x}}-\mathrm{GO}-80$, and (d) the iron oxide $\left(\mathrm{Fe}_{3} \mathrm{O}_{4}\right)$ control sample.

Figure S6 in Supporting Information shows the Raman spectra of $\mathrm{GO}, \mathrm{FeO}_{\mathrm{x}}-\mathrm{GO}-36, \mathrm{FeO}_{\mathrm{x}}-\mathrm{GO}-$ 80, and the $\mathrm{Fe}_{3} \mathrm{O}_{4}$ control sample. Within the low wavenumber range (150-850 $\left.\mathrm{cm}^{-1}\right), \mathrm{FeO}_{\mathrm{x}}-\mathrm{GO}-$ 36, $\mathrm{FeO}_{\mathrm{x}}-\mathrm{GO}-80$, and the $\mathrm{Fe}_{3} \mathrm{O}_{4}$ control sample show similar spectra with no distinct difference 
despite their different crystal structures, with Raman peaks observed at 218,290 , and $400 \mathrm{~cm}^{-1}$. In addition, the defect band at $1350 \mathrm{~cm}^{-1}$ and the graphene band at $1610 \mathrm{~cm}^{-1}$ are present in GO and the two composites, with the former indicative of the defects in the graphene moiety. The intensity ratio $\left(\mathrm{I}_{\mathrm{D}} / \mathrm{I}_{\mathrm{G}}\right)$ of the defect band to the graphene band increases from 0.79 in GO to 0.93 and 0.95 for $\mathrm{FeO}_{\mathrm{x}}-\mathrm{GO}-36$ and $\mathrm{FeO}_{\mathrm{x}}-\mathrm{GO}-80$, respectively, indicating the chemical interaction/complexation between the iron oxide and the moieties on GO [51].

The $\mathrm{FeO}_{\mathrm{x}}-\mathrm{GO}$ composites, along with $\mathrm{GO}$ and the iron oxide control sample, were further characterized with $\mathrm{N}_{2}$ sorption analysis at $77 \mathrm{~K}$ for their textural properties. Table 1 summarizes the characterization data, including surface area, pore volume, and average meso-/macro-pore size. Figure 6(a) shows their $\mathrm{N}_{2}$ adsorption-desorption curves. All samples except the iron oxide control sample show type IV adsorption isotherms, with the steep adsorption at low relative pressure range $(0-0.1)$ and the presence of a $\mathrm{H} 2$ type hysteresis loop in the medium to high relative pressure range $(0.4-0.9)$ [53]. This indicates these samples contain both micropores and mesopores. The iron oxide control sample instead shows only a slight uptake at the low relative pressure end $\left(P / P_{0}<0.05\right)$, and a sharp uptake with a $\mathrm{H} 3$ type hysteresis loop at high relative pressure end $\left(P / P_{0}>0.9\right)$ [53], indicating that the sample contains predominantly large mesopores and/or macropores (average size: $28 \mathrm{~nm}$ ). In this sample, the mesopores/macropores should be the inter-nanoparticle pores resulting from the aggregation/packing of the crystalline $\mathrm{Fe}_{3} \mathrm{O}_{4}$ nanoparticles. $\mathrm{GO}$ and the iron oxide control sample have a surface area of 129 and $71 \mathrm{~m}^{2}$ $\mathrm{g}^{-1}$, respectively, and a pore volume of 0.09 and $0.36 \mathrm{~cm}^{3} \mathrm{~g}^{-1}$, respectively. On the basis of its surface area and magnetite density $\left(5.18 \mathrm{~g} \mathrm{~cm}^{-1}\right)[10]$, the crystalline $\mathrm{Fe}_{3} \mathrm{O}_{4}$ nanoparticles in the iron oxide control sample have an estimated average diameter of $16 \mathrm{~nm}$, which is nearly identical to the average size estimated above from XRD or TEM. 

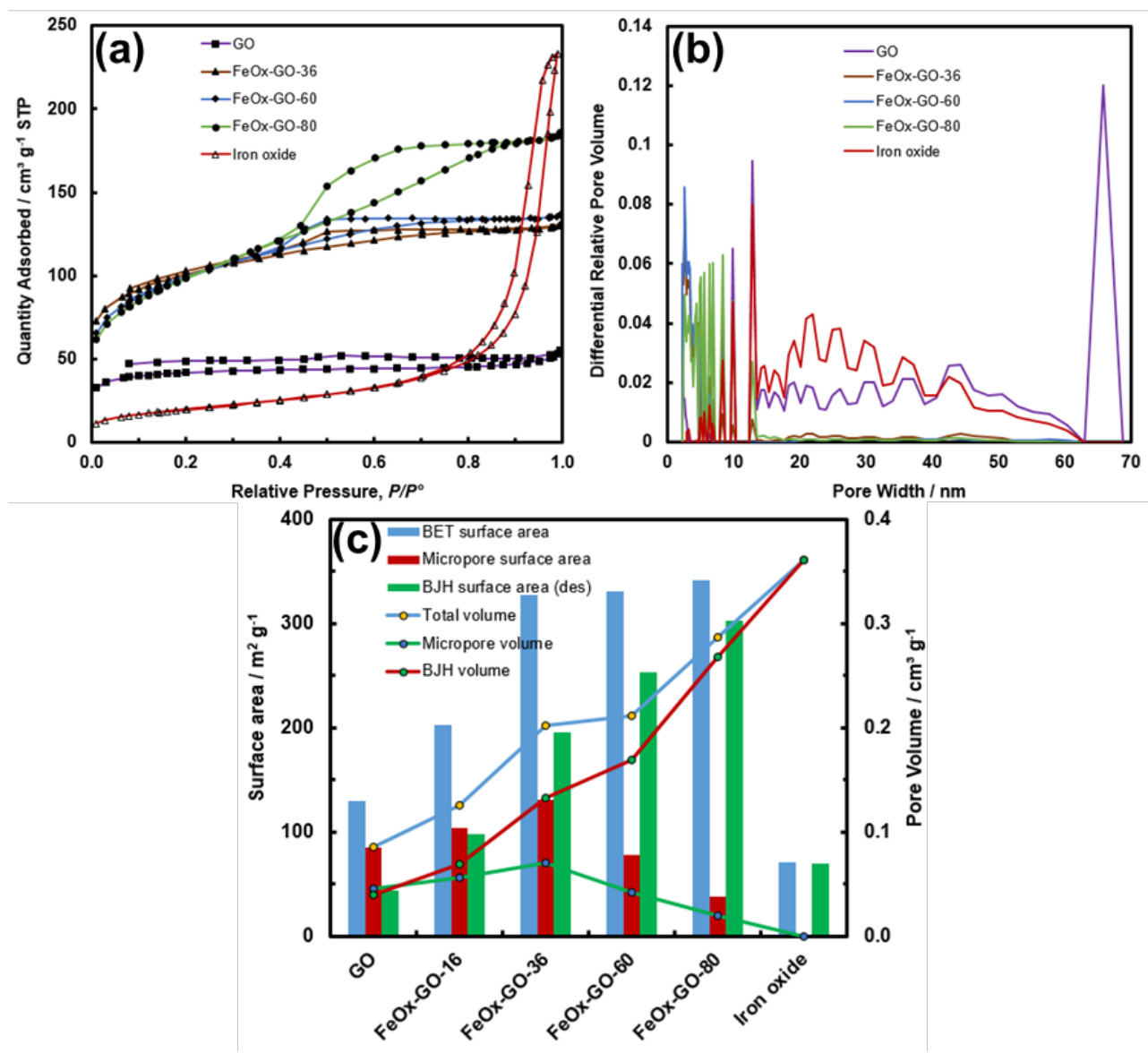

Figure 6. (a) $\mathrm{N}_{2}$ adsorption-desorption isotherm of $\mathrm{FeO}_{\mathrm{x}}-\mathrm{GO}$ composites, $\mathrm{GO}$, and the iron oxide control sample, (b) DFT meso-/macro-pore size distribution curves, (c) dependencies of surface area and pore volume data on the iron oxide content. 


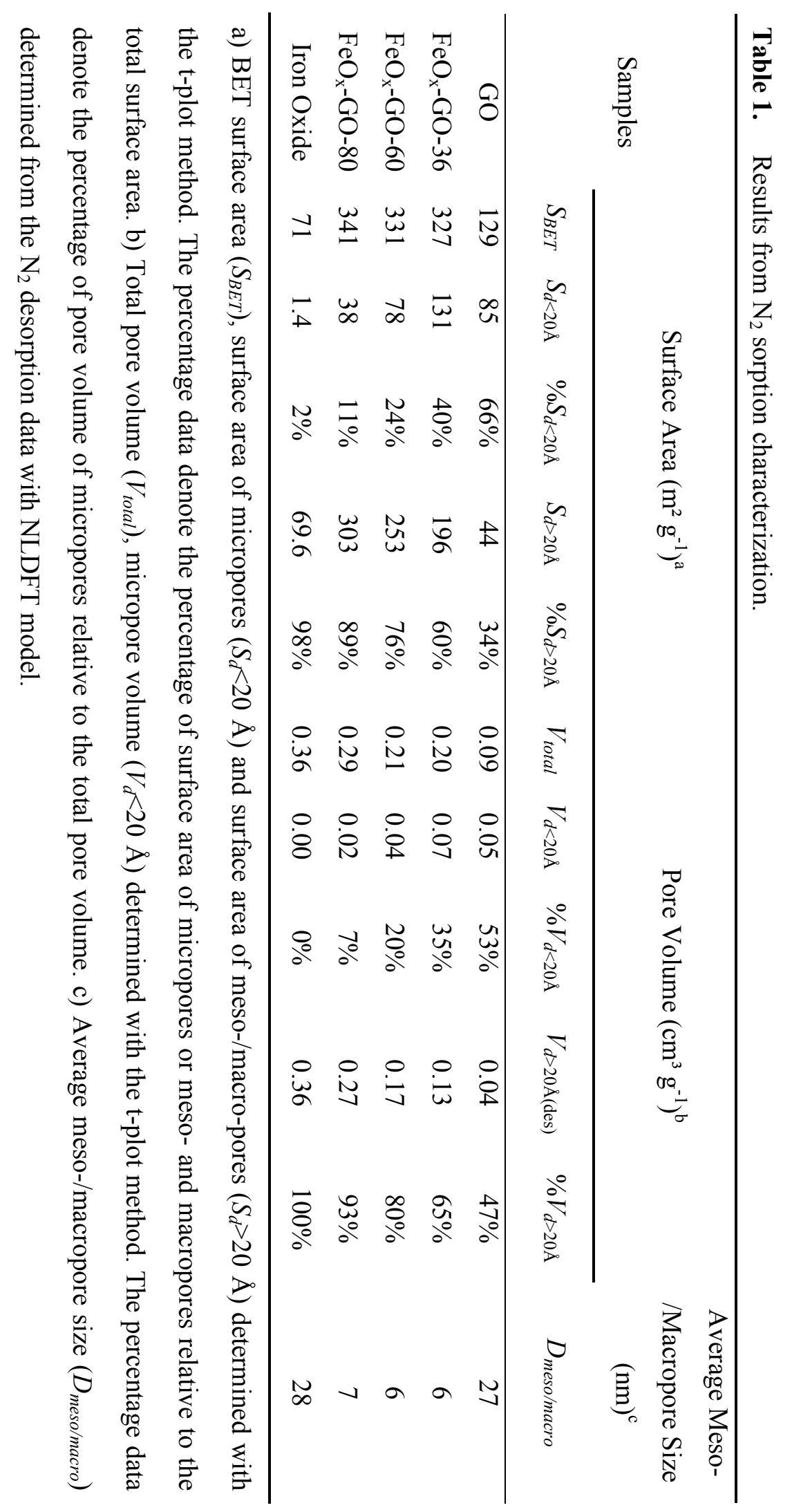


Relative to $\mathrm{GO}$ and the crystalline $\mathrm{Fe}_{3} \mathrm{O}_{4}$ control sample, the three composites show significantly enhanced surface area $\left(327-341 \mathrm{~m}^{2} \mathrm{~g}^{-1}\right)$ and pore volume $\left(0.20-0.29 \mathrm{~cm}^{3} \mathrm{~g}^{-1}\right)$. Meanwhile, both surface area and pore volume show slight increases with the increase of the iron oxide content from $\mathrm{FeO}_{\mathrm{x}}-\mathrm{GO}-36$ to $\mathrm{FeO}_{\mathrm{x}}-\mathrm{GO}-80$. From the data in Table 1 and the pore size distribution in Figure 6(b), the enhanced surface area and pore volume arise mainly from the generation of more mesopores with sizes $\leq 12 \mathrm{~nm}$. Both the micropore surface area and micropore volume of the composites show a trend of decrease with the increase of iron oxide content (see Figure 6(c) and Table 1). Relative to the value of about $27 \mathrm{~nm}$ for both $\mathrm{GO}$ and the iron oxide control sample, the average meso-/macropore size of the composites is about $7 \mathrm{~nm}$, which is in the same range as the average size (ca. $5 \mathrm{~nm}$ ) of the amorphous iron oxide nanoparticles seen above from the TEM images. This indicates that the generated mesopores are primarily inter-particle pores resulting from the packing/aggregation of the amorphous iron oxide nanoparticles. The surface area data of the three composites are also significantly higher than those of other iron oxide-GO/RGO nanocomposites [23,30] and various iron oxide nanostructures [13-21] reported in the literature. Clearly, the loading of the amorphous iron oxide nanoparticles on GO renders enhanced surface area and pore volume through the creation of more mesopore structures, which is beneficial to arsenic adsorption due to the increased active sites for the adsorption as shown below.

Unlike the composites herein, the iron oxides present in other iron oxide-GO/RGO composites reported in the literature for arsenic adsorption are often in the form of crystalline nanoparticles, despite very similar synthesis procedures and conditions as we used herein [23-33]. Though a precise mechanism is not known, we reason that this results from the different GO/RGO substrates employed, which affects the morphology of the loaded iron oxides. The exclusive formation of crystalline $\mathrm{Fe}_{3} \mathrm{O}_{4}$ nanoparticles in the control sample prepared in the absence of $\mathrm{GO}$ herein supports this hypothesis. The GO substrate synthesized herein via the improved method should be more oxidized than those commonly synthesized via the Hummers or modified 
Hummers method for the preparation of composites in the literature. The higher level of oxidation likely improves the complexation of iron species with GO, inhibits the formation of crystallization nuclei, and thus promotes the formation of amorphous iron oxide nanoparticles.

\subsection{Arsenic Adsorption with $\mathrm{FeO}_{\mathrm{x}}-\mathrm{GO}$ Nanocomposites}

The performance of the $\mathrm{FeO}_{\mathrm{x}}-\mathrm{GO}$ nanocomposites for batch adsorption of both $\mathrm{As}(\mathrm{III})$ and $\mathrm{As}(\mathrm{V})$ has been systematically investigated, along with GO and the iron oxide control sample for comparison. The effect of the dosage $\left(0.1-1 \mathrm{mg} \mathrm{mL}^{-1}\right)$ of $\mathrm{FeO}_{\mathrm{x}}-\mathrm{GO}-80$ on the adsorption of $\mathrm{As}(\mathrm{III})($ at $\mathrm{pH}=7)$ and $\mathrm{As}(\mathrm{V})($ at $\mathrm{pH}=3)$ was first studied at the initial concentration of 1200 and $350 \mathrm{mg} \mathrm{L}^{-1}$, respectively. The $\mathrm{pH}$ values were so chosen as to achieve optimum adsorption as shown below in the study on the effects of $\mathrm{pH}$. Figure $\mathrm{S} 7$ shows the dependencies of the equilibrium adsorption amount $\left(q_{e}\right)$ on the adsorbent dosage. In general, $q_{e}$ changes only marginally across the whole adsorbent dosage range, with the highest values obtained at the dosage of $0.8 \mathrm{mg} \mathrm{mL}^{-1}$ for both $\mathrm{As}(\mathrm{III})$ and $\mathrm{As}(\mathrm{V})$. The adsorbent dosage of $0.8 \mathrm{mg} \mathrm{mL}^{-1}$ was thus chosen for all subsequent investigations.

Figure 7 shows the arsenic adsorption isotherms of the various composite adsorbents as well as of GO and the iron oxide control sample in a broad equilibrium concentration range. The initial arsenic concentrations are $25-1200 \mathrm{mg} \mathrm{L}^{-1}$ for $\mathrm{As}(\mathrm{III})$ at $\mathrm{pH}=7$ and $25-350 \mathrm{mg} \mathrm{L}^{-1}$ for $\mathrm{As}(\mathrm{V})$ at $\mathrm{pH}=3$. All the isotherms have been found to follow the Langmuir adsorption model (Equation 2) well with the high correlation coefficients $\left(\mathrm{R}^{2} \approx 1\right.$, see Table $\mathrm{S} 1$ for fitting results) found. On the contrary, the isotherms do not fit the Freundlich model well (see Figure S8 and Table S2). Particularly, no Freundlich fitting can be made with respect to the As(V) adsorption isotherms of the nanocomposite adsorbents or the $\mathrm{Fe}_{3} \mathrm{O}_{4}$ control sample. This suggests that the adsorption of 
both $\mathrm{As}(\mathrm{III})$ and $\mathrm{As}(\mathrm{V})$ with the adsorbents herein can be regarded as monolayer adsorption processes.
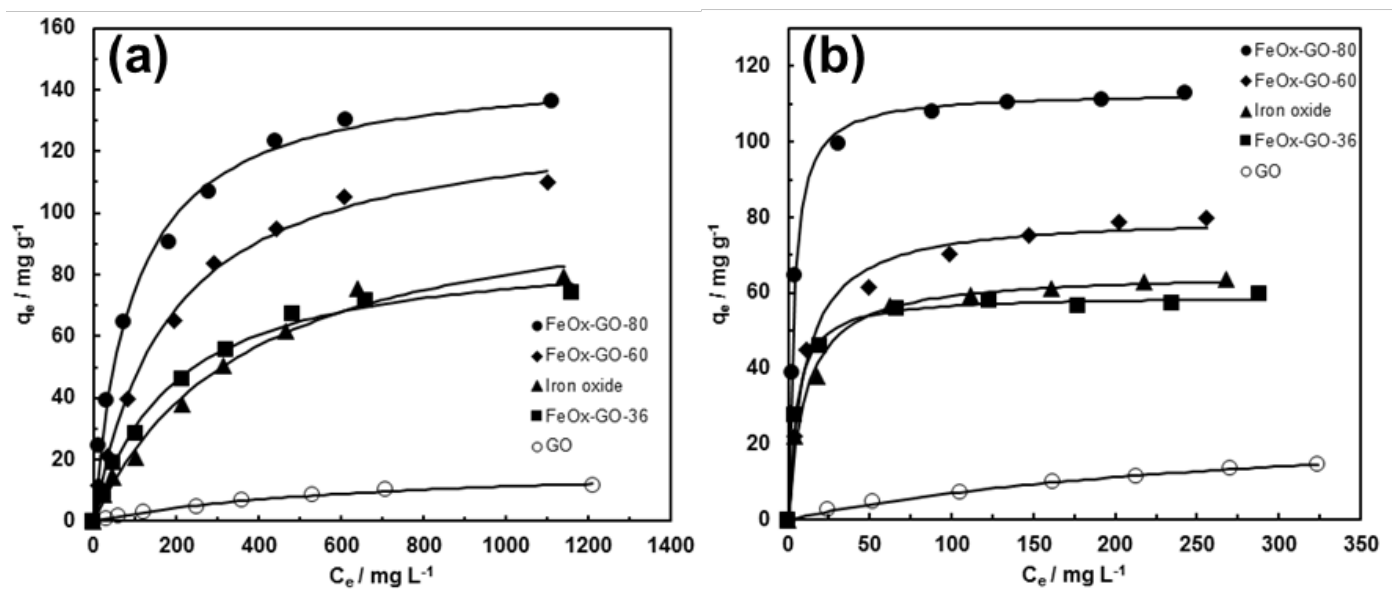

Figure 7. (a) As(III) adsorption isotherms (at $\mathrm{pH}=7$ ) and (b) $\mathrm{As}(\mathrm{V})$ adsorption isotherms (at $\mathrm{pH}=3$ ) of $\mathrm{FeO}_{\mathrm{x}}-\mathrm{GO}$ nanocomposites, $\mathrm{GO}$, and the iron oxide control sample. All the isotherms are well fitted with the Langmuir model (solid line).

Among the adsorbents, GO shows the poorest adsorption performance with the lowest isotherms. Its maximum/saturated adsorption capacity $\left(q_{\max }\right)$ is only 19 and $28 \mathrm{mg} \mathrm{g}^{-1}$ for $\mathrm{As}(\mathrm{III})$ and $\mathrm{As}(\mathrm{V})$, respectively. The iron oxide control sample $\left(q_{\max }\right.$ values of 110 and $\left.65 \mathrm{mg} \mathrm{g}^{-1}\right)$ has its isotherms nearly overlapping with those of $\mathrm{FeO}_{\mathrm{x}}-\mathrm{GO}-36\left(q_{\max }\right.$ values of 90 and $\left.59 \mathrm{mg} \mathrm{g}^{-1}\right)$, indicating their similar adsorption performance. Despite its lower surface area, the much higher $q_{\max }$ values found with the iron oxide control sample than those with GO confirms the significantly higher affinity of the iron oxide surface for the arsenic species. With the increase of iron oxide content from $\mathrm{FeO}_{\mathrm{x}}-\mathrm{GO}-36$ to $\mathrm{FeO}_{\mathrm{x}}-\mathrm{GO}-80$, the isotherms for both $\mathrm{As}(\mathrm{III})$ and $\mathrm{As}(\mathrm{V})$ continuously shift upward, indicating the improved adsorption. $\mathrm{FeO}_{\mathrm{x}}-\mathrm{GO}-80$ is featured with highest $q_{\max }$ values of 147 and $113 \mathrm{mg} \mathrm{g}^{-1}$ for $\mathrm{As}(\mathrm{III})$ and $\mathrm{As}(\mathrm{V})$, respectively, among all the adsorbents. While the surface area of three composites are only slightly different, the significant increase in $q_{\max }$ from 
$\mathrm{FeO}_{\mathrm{x}}-\mathrm{GO}-36$ to $\mathrm{FeO}_{\mathrm{x}}-\mathrm{GO}-80$ possibly results from the generation of significantly more iron oxide active sites of higher adsorption affinity per unit area with the increase of iron oxide content. Meanwhile, the increase in the more accessible mesopore surface area, along with the reduction in micropore surface area, upon the increase of iron oxide content as shown above also endows the improved accessibility of the active sites.

Table 2. Comparison of maximum arsenic adsorption capacities achieved with iron oxideGO/RGO nanocomposites.

\begin{tabular}{|c|c|c|c|c|c|}
\hline \multirow{2}{*}{ Adsorbent } & \multirow{2}{*}{ Iron oxide content } & \multirow{2}{*}{$\begin{array}{c}\mathrm{S}_{\mathrm{BET}} \\
\left(\mathrm{m}^{2} / \mathrm{g}\right)\end{array}$} & \multicolumn{2}{|c|}{$q_{\max }\left(\mathrm{mg} \mathrm{g}^{-1}\right)$} & \multirow{2}{*}{ Reference } \\
\hline & & & $\operatorname{As}(\mathbf{I I I})$ & $\operatorname{As}(V)$ & \\
\hline $\begin{array}{l}\text { Amorphous iron oxide-GO } \\
\text { nanocomposites }\end{array}$ & $\begin{array}{l}80 \mathrm{wt} \% \text { of } \\
\text { amorphous iron } \\
\text { oxide }\end{array}$ & 341 & 147 & 113 & this study \\
\hline $\mathrm{Fe}_{3} \mathrm{O}_{4}-\mathrm{RGO}$ composites & $75 \mathrm{wt} \%$ of $\mathrm{Fe}_{3} \mathrm{O}_{4}$ & 117 & 13.10 & 5.83 & [23] \\
\hline $\mathrm{Fe}(\mathrm{OH})_{3}$-GO composites & $54 \mathrm{wt} \%$ of $\mathrm{Fe}(\mathrm{OH})_{3}$ & & & 23.78 & [24] \\
\hline $\begin{array}{l}\mathrm{Fe}_{3} \mathrm{O}_{4}-\mathrm{GO}-\mathrm{LDH} \\
\text { composites }\end{array}$ & $21.1 \mathrm{wt} \%$ of $\mathrm{Fe}_{3} \mathrm{O}_{4}$ & 123.3 & & 73.14 & {$[25]$} \\
\hline $\mathrm{Fe}_{3} \mathrm{O}_{4}$-GO composites & $80 \%$ of $\mathrm{Fe}_{3} \mathrm{O}_{4}$ & & & 59.6 & {$[26]$} \\
\hline $\begin{array}{l}\mathrm{Fe}-\mathrm{Fe}_{2} \mathrm{O}_{3} \text {-graphene } \\
\text { nanoplatelet composites }\end{array}$ & & & 11.34 & & {$[27]$} \\
\hline Fe-GO nanocomposites & & 165 & & 3.26 & {$[30]$} \\
\hline $\begin{array}{l}\mathrm{Fe}_{3} \mathrm{O}_{4}-\mathrm{RGO} \\
\text { nanocomposites }\end{array}$ & & & 7.5 & 16 & {$[31]$} \\
\hline $\begin{array}{l}\alpha-\mathrm{Fe}_{2} \mathrm{O}_{3}-\mathrm{Fe}_{3} \mathrm{O}_{4}-\mathrm{GO} \\
\text { composite }\end{array}$ & $\begin{array}{c}51.7 \mathrm{wt} \% \text { of iron } \\
\text { oxide }\end{array}$ & & 26.76 & 54.18 & {$[32]$} \\
\hline $\mathrm{Fe}_{3} \mathrm{O}_{4}-\mathrm{RGO}$ composite & & & & 3.36 & [33] \\
\hline
\end{tabular}

The $q_{\max }$ values found with $\mathrm{FeO}_{\mathrm{x}}-\mathrm{GO}-80$ herein are the highest among all the iron oxideGO/RGO composite adsorbents reported to date and are also comparable to the best values achieved thus far with various sophisticatedly synthesized iron oxide nanostructures [13-20]. Table 2 compares the arsenic adsorption capacity achieved with various iron oxide-GO/RGO composite adsorbents. Meanwhile, all the $\mathrm{FeO}_{\mathrm{x}}-\mathrm{GO}$ nanocomposites and the iron oxide control sample show higher $q_{\max }$ for As(III) than for As(V), while opposite for GO. This suggests the 
different interactions of the arsenic species with the adsorbents. It is desirable because of the prevalence of $\mathrm{As}(\mathrm{III})$ in groundwater and wastewater, which has higher toxicity than $\mathrm{As}(\mathrm{V})[1-$ $3]$.

Not only featured with high adsorption capacity in the high arsenic concentration range, $\mathrm{FeO}_{\mathrm{x}^{-}}$ GO-80 also exhibits superior arsenic removal efficiency at the low arsenic concentration range. At the low initial arsenic concentrations (118 and $108 \mu \mathrm{g} \mathrm{L} \mathrm{L}^{-1}$ for $\mathrm{As}(\mathrm{III})$ and $\mathrm{As}(\mathrm{V})$, respectively, with $\mathrm{pH}$ of 6.5 typical for drinking waters), the equilibrium arsenic concentration after adsorption with $\mathrm{FeO}_{\mathrm{x}}-\mathrm{GO}-80$ at the dosage of $0.8 \mathrm{mg} \mathrm{mL}^{-1}$ can be reduced to lower than $0.02 \mu \mathrm{g}$ $\mathrm{L}^{-1}$ for both $\mathrm{As}(\mathrm{III})$ and $\mathrm{As}(\mathrm{V})$, which is much lower than the maximum arsenic level of $10 \mu \mathrm{g} \mathrm{L^{- }}$ ${ }^{1}$ suggested by World Health Organization (WHO) for drinking water [54]. This corresponds to $>99.98 \%$ of arsenic removal. No other adsorbents have been previously demonstrated to remove arsenic to such a low concentration. With a high-performance $\gamma-\mathrm{Fe}_{2} \mathrm{O}_{3}$-macroporous silica composite adsorbent [38], Yu et al. previously reported to reduce the arsenic concentration to $<2$ $\mu \mathrm{g} \mathrm{\textrm {L } ^ { - 1 }}$ from the initial arsenic concentration of $100 \mu \mathrm{g} \mathrm{L}^{-1}$. In this regard, $\mathrm{FeO}_{\mathrm{x}}-\mathrm{GO}-80$ well competes with it while with the advantage of more convenient, cost effective synthesis.

Figure 8(a) shows the adsorption kinetics curves with $\mathrm{FeO}_{\mathrm{x}}-\mathrm{GO}-80$ as the adsorbent at initial arsenic concentration of 400 and $350 \mathrm{mg} \mathrm{L}^{-1}$ for $\mathrm{As}(\mathrm{III})$ and $\mathrm{As}(\mathrm{V})$, respectively. For both $\mathrm{As}(\mathrm{III})$ and $\mathrm{As}(\mathrm{V})$, the adsorption can be divided into two stages, a rapid uptake within the first 15 min of contact and a slow uptake thereafter until equilibrium is reached. In particular, the majority of the arsenic uptake, 70 and $77 \%$ for $\mathrm{As}(\mathrm{III})$ and $\mathrm{As}(\mathrm{V})$, respectively, occurs within the first $15 \mathrm{~min}$, indicating the very fast adsorption rate. The pseudo-second-order kinetic model (Equations 3 and 4), widely used to fit the kinetic process of metal ion adsorption at the solid/water interfaces, is employed to fit the curves. Excellent fitting of the experimental data is achieved with the model, with the correlation coefficients of 0.9998 and 0.9992 , respectively 
(see Figure 8(b) and Table S1), indicating the adsorption process occurs through the chemical interaction [55]. Meanwhile, the adsorption rates for both As(III) and As(V) are similarly high, with the same rate constant $k_{2}$ of $0.001 \mathrm{~g} \mathrm{mg}^{-1} \mathrm{~min}^{-1}$ achieved. The $k_{2}$ value is very high, in particular for As(III), when compared to other superior adsorbents reported in the literature. For example, the high-performance $\gamma-\mathrm{Fe}_{2} \mathrm{O}_{3}$-macroporous silica composite adsorbent reported by $\mathrm{Yu}$ et al. has the $k_{2}$ values of 0.00015 and $0.0014 \mathrm{~g} \mathrm{mg}^{-1} \mathrm{~min}^{-1}$ for $\mathrm{As}(\mathrm{III})$ and $\mathrm{As}(\mathrm{V})$, respectively, under similar conditions [38]. Therein, the adsorption rate for As(III) is 10 times slower than for $\mathrm{As}(\mathrm{V})$. The significantly high adsorption rate found with $\mathrm{FeO}_{\mathrm{x}}-\mathrm{GO}-80$ for more toxic $\mathrm{As}(\mathrm{III})$ is thus remarkable, confirming its superior kinetics performance.
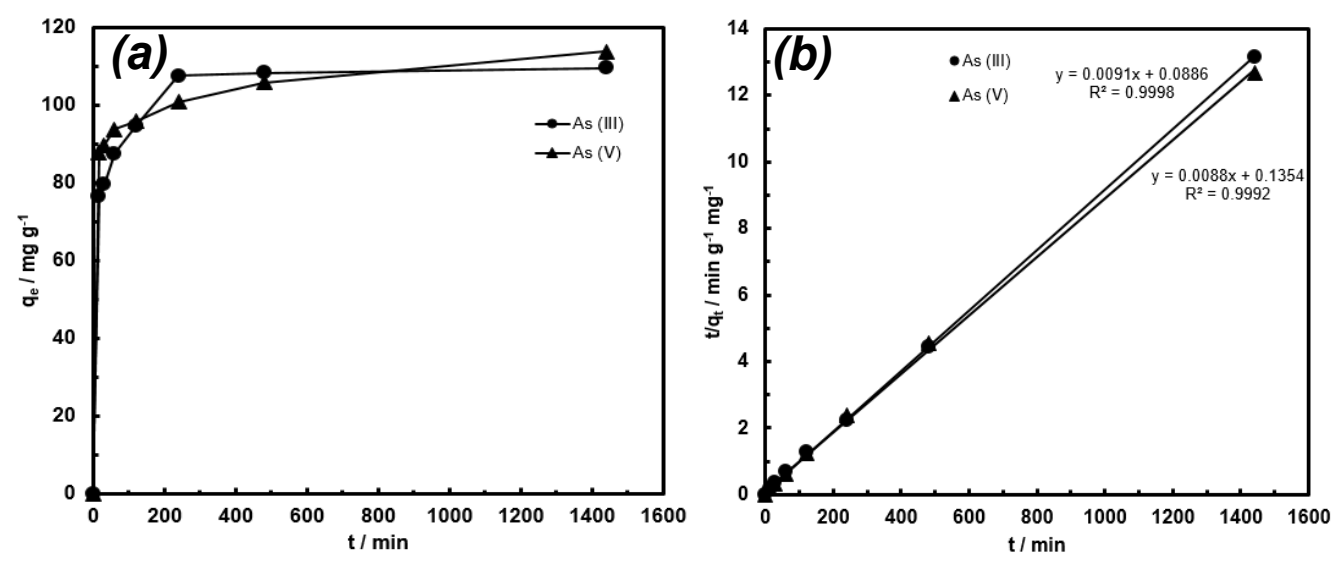

Figure 8. (a) $\mathrm{As}(\mathrm{III})$ and $\mathrm{As}(\mathrm{V})$ adsorption kinetic curves with $\mathrm{FeO}_{\mathrm{x}}-\mathrm{GO}-80$ (initial arsenic concentration of 400 and $350 \mathrm{mg} \mathrm{L}^{-1}$ for $\mathrm{As}(\mathrm{III})(\mathrm{pH}=7)$ and $\mathrm{As}(\mathrm{V})(\mathrm{pH}=3)$, respectively; (b) fitting of the kinetic curves with the pseudo-second-order model.

The effects of the $\mathrm{pH}$ of the medium on arsenic adsorption have also been investigated since it changes the surface charge of $\mathrm{FeO}_{\mathrm{x}}-\mathrm{GO}$ composites and arsenic species distribution [1-4]. Figure 9(a) shows $q_{e}$ as a function of $\mathrm{pH}$ (within 2-10) with $\mathrm{FeO}_{\mathrm{x}}-\mathrm{GO}-80$ at the initial $\mathrm{As}(\mathrm{III})$ and $\mathrm{As}(\mathrm{V})$ concentration of $350 \mathrm{mg} \mathrm{L}^{-1}$. With the increase of $\mathrm{pH}$ from 2 to $10, q_{e}$ for $\mathrm{As}(\mathrm{V})$ keeps dropping from $118 \mathrm{mg} \mathrm{g}^{-1}$ at $\mathrm{pH}=2$ to $55 \mathrm{mg} \mathrm{g}^{-1}$ at $\mathrm{pH}=10$. On the contrary, $q_{e}$ for As(III) stays nearly at 
a plateau (105 $\left.\mathrm{mg} \mathrm{g}^{-1}\right)$ within the $\mathrm{pH}$ range of $7-10$ and shows a steady drop to $70 \mathrm{mg} \mathrm{g}^{-1}$ with the decrease of $\mathrm{pH}$ from 7 to 2. Similar trends of the effects of $\mathrm{pH}$ have commonly been observed with iron oxide-based adsorbents and can be explained by the changes in surface charge of the adsorbents and the arsenic speciation [7-9,12,21-24,26,32,34,37,38]. Figure 9(b) shows the dependence of surface charge of $\mathrm{FeO}_{\mathrm{x}}-\mathrm{GO}-80$ on $\mathrm{pH}$. Increasing $\mathrm{pH}$ leads to a continuous decrease of its surface charge, with the point of zero charge $\left(\mathrm{pH}_{\mathrm{PZC}}\right)$ being about 5.9. Its surface is positively charged at $\mathrm{pH}<\mathrm{pH}_{\mathrm{PZC}}$. Under most $\mathrm{pH}$ conditions, $\mathrm{As}(\mathrm{V})$ is present in negative ionic form $\left(\mathrm{H}_{2} \mathrm{AsO}_{4}{ }^{-}\right.$at $\mathrm{pH}$ 2.2-6.5, $\mathrm{HAsO}_{4}{ }^{2-}$ at $\mathrm{pH}$ 6.5-11.5), whereas As(III) is in a neutral form $\left(\mathrm{H}_{3} \mathrm{AsO}_{3}\right.$ at $\mathrm{pH}$ below 9.2) [2]. The electrostatic interactions between positively charged $\mathrm{FeO}_{\mathrm{x}}-\mathrm{GO}-80$ and negatively charged $\mathrm{As}(\mathrm{V})$ species result in the strong adsorption of $\mathrm{FeO}_{\mathrm{x}}-\mathrm{GO}-80$ when $\mathrm{pH}<\mathrm{pH}_{\mathrm{PZC}}$. The surface of $\mathrm{FeO}_{\mathrm{x}}-\mathrm{GO}-80$ is negatively charged at $\mathrm{pH}>$ $\mathrm{pH}_{\mathrm{PZC}}$, repulsing the negatively charged $\mathrm{As}(\mathrm{V})$ species. As such, increasing the $\mathrm{pH}$ leads to continuous reductions in $q_{e}$ for $\mathrm{As}(\mathrm{V})$.

However, the adsorption mechanism of $\mathrm{As}(\mathrm{III})$ on $\mathrm{FeO}_{\mathrm{x}}-\mathrm{GO}-80$ is different given the opposite trend of change. We first suspected that the lower As(III) uptake at the acidic conditions (2-6) might result from the dissolution and leaching of the iron oxide species from $\mathrm{FeO}_{\mathrm{x}}-\mathrm{GO}-80$ into the solution [23]. This was, however, ruled out. No Fe species was detected within the detection limit $(<0.5 \mathrm{ppm})$ of atomic absorption spectroscopy in the equilibrium solutions even at the highly acidic condition with $\mathrm{pH}=2$, demonstrating the strong binding of the iron oxide species on GO. The results suggest that $\mathrm{As}(\mathrm{III})$ is adsorbed onto $\mathrm{FeO}_{\mathrm{x}}-\mathrm{GO}-80$ through a surface complexation mechanism, rather than electrostatic interactions [23]. The adsorption capacity increase with increasing $\mathrm{pH}$ may be attributed to the enhanced surface hydroxyl groups at higher $\mathrm{pH}$ values for complexation [37]. Similar patterns of dependence have been noted in the literature [37]. However, the precise mechanism is currently still unknown and requires further investigation. 

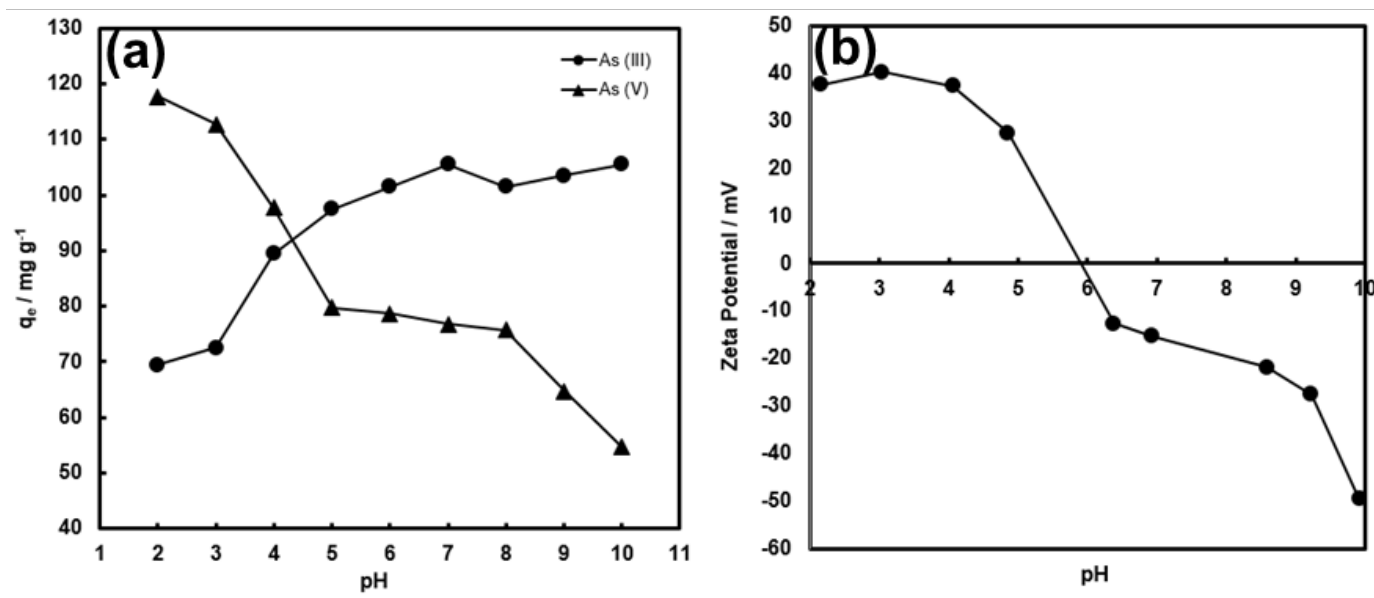

Figure 9. (a) Arsenic uptake of $\mathrm{FeO}_{\mathrm{x}}-\mathrm{GO}-80$ as a function of $\mathrm{pH}$ (initial arsenic concentration of $350 \mathrm{mg} \mathrm{L}^{-1}$ ); (b) Zeta potential of $\mathrm{FeO}_{\mathrm{x}}-\mathrm{GO}-80$ as a function of $\mathrm{pH}$.

We have also examined the effects of coexisting anions $\left(\mathrm{SO}_{4}{ }^{2-}, \mathrm{CO}_{3}{ }^{2-}\right.$, and $\left.\mathrm{PO}_{4}{ }^{3-}\right)$ on the arsenic adsorption with $\mathrm{FeO}_{\mathrm{x}}-\mathrm{GO}-80$ (dosage: $0.8 \mathrm{mg} \mathrm{mL}^{-1}$ ) at the low initial arsenic concentration (118 and $108 \mu \mathrm{g} \mathrm{L}^{-1}$ for $\mathrm{As}(\mathrm{III})$ and $\mathrm{As}(\mathrm{V})$, respectively) and at the initial $\mathrm{pH}$ of 6.5 (i.e., mimicking drinking water). To simulate the extreme situations, the concentration of the coexisting anions is set excessively high, with molar concentration being 1,000 times that of arsenic. Figure 10 shows the residual arsenic concentrations achieved after the adsorption. In the presence of $\mathrm{SO}_{4}{ }^{2-}, \mathrm{CO}_{3}{ }^{2-}$, and $\mathrm{PO}_{4}{ }^{3-}, \mathrm{As}(\mathrm{III})$ concentration is effectively reduced to $<0.02,<0.02$, and $10 \mu \mathrm{g} \mathrm{L} \mathrm{L}^{-1}$, respectively, and $\mathrm{As}(\mathrm{V})$ concentration is correspondingly reduced to $<0.02,22$, and $76 \mu \mathrm{g} \mathrm{L} \mathrm{L}^{-1}$, respectively. Clearly, the presence of $\mathrm{SO}_{4}{ }^{2-}$ has no appreciable effect on the adsorption of both $\mathrm{As}(\mathrm{III})$ and $\mathrm{As}(\mathrm{V}) . \mathrm{CO}_{3}{ }^{2-}$ shows negligible impact on $\mathrm{As}(\mathrm{III})$ adsorption but slightly reduces the adsorption of $\mathrm{As}(\mathrm{V})$. Its effect on $\mathrm{As}(\mathrm{V})$ adsorption may be explained by an increase in $\mathrm{pH}$ after its dissolution in the arsenic solution [32]. Though causing only a small reduction in the adsorption of $\mathrm{As}(\mathrm{III}), \mathrm{PO}_{4}{ }^{3-}$ shows the expected most intense reduction in the adsorption of $\mathrm{As}(\mathrm{V}) . \mathrm{PO}_{4}{ }^{3-}$ is a known strong competing anion for arsenic adsorption and can strongly compete 
with arsenic for adsorption sites [26,32,34] Its effect can be explained by the similar tetrahedral structure formed by $\mathrm{As}(\mathrm{V}), \mathrm{As}(\mathrm{III})$, and phosphate [32]. Despite the excessive presence of the coexisting anions, these results confirm that the concentration of more toxic As(III) can be effectively removed with $\mathrm{FeO}_{\mathrm{x}}-\mathrm{GO}-80$ to the level $\left(10 \mu \mathrm{g} \mathrm{L}^{-1}\right)$ meeting the WHO guidelines for drinking water. However, in extreme situations where the drinking water contains large quantities of $\mathrm{SO}_{4}{ }^{2-}$ and $\mathrm{PO}_{4}{ }^{3-}$, particularly the latter, a higher adsorbent dosage will be required in order to reduce $\mathrm{As}(\mathrm{V})$ concentration to the required level.

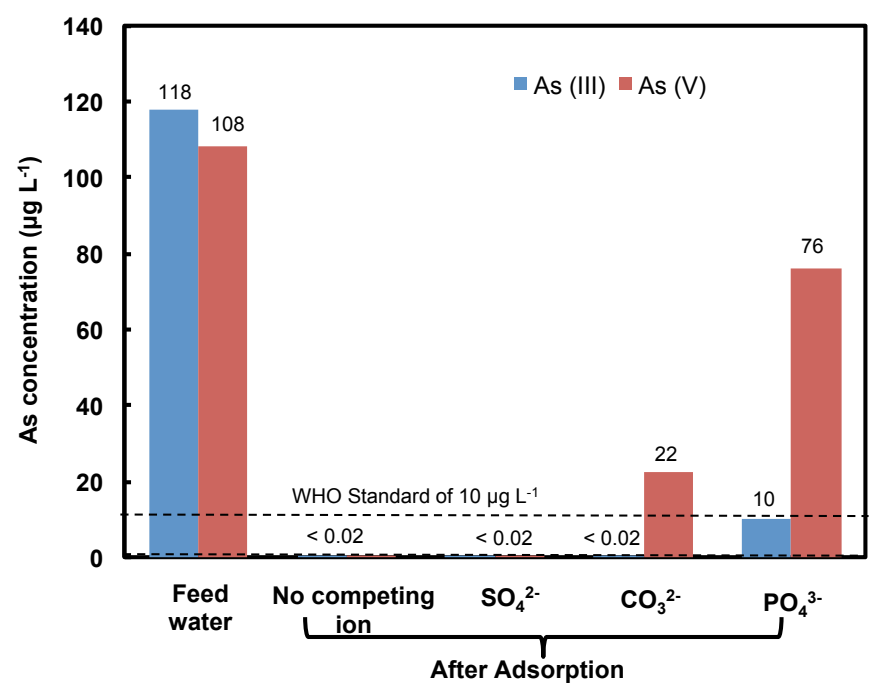

Figure 10. Residual arsenic concentration in the water containing different competing ions after adsorption with $\mathrm{FeO}_{\mathrm{x}}-\mathrm{GO}-80$ (initial $\mathrm{As}(\mathrm{III})$ and $\mathrm{As}(\mathrm{V})$ concentrations: 118 and $108 \mathrm{mg} \mathrm{mL}^{-1}$, respectively; competing ion concentration, 1,000 times those of arsenic; initial $\mathrm{pH}, 6.5$ ).

\section{Conclusion}

Iron oxide-GO nanocomposite adsorbents $\left(\mathrm{FeO}_{\mathrm{x}}-\mathrm{GO}-36, \mathrm{FeO}_{\mathrm{x}}-\mathrm{GO}-60, \mathrm{FeO}_{\mathrm{x}}-\mathrm{GO}-80\right)$ having different iron oxide content, as well as the iron oxide control sample, have been synthesized and 
investigated for arsenic removal. Detailed characterization of the nanocomposites has been undertaken systematically with TGA, TEM, FTIR, XPS, XRD, Raman, and $\mathrm{N}_{2}$ sorption. In particular, the evidence from XRD and TEM confirms that the iron oxide is primarily in the form of amorphous iron oxide nanoparticles (ca. $5 \mathrm{~nm}$ in size), which distribute uniformly in the nanocomposites, along with a minor presence of crystalline $\alpha-\mathrm{Fe}_{2} \mathrm{O}_{3}$. On the contrary, the iron oxide control sample prepared in the absence of $\mathrm{GO}$ is crystalline $\mathrm{Fe}_{3} \mathrm{O}_{4}$, demonstrating the pronounced inhibiting effects of the GO substrate on crystal formation in the nanocomposites. The nanocomposites have significantly enhanced surface area $\left(327-341 \mathrm{~m}^{2} / \mathrm{g}\right)$ relative to GO and the crystalline iron oxide control sample, which shows slight increases with the increase of iron oxide content.

The nanocomposite adsorbents show significantly high arsenic adsorption capacities relative to GO and the iron oxide control sample. Increased arsenic adsorption capacities are found with the increase of iron oxide content due to the increase in surface area and the generation of more accessible active sites. In particular, $\mathrm{FeO}_{\mathrm{x}}-\mathrm{GO}-80$ shows high $q_{\max }$ values of 147 and $113 \mathrm{mg} \mathrm{g}^{-1}$ for $\mathrm{As}(\mathrm{III})$ and $\mathrm{As}(\mathrm{V})$, respectively, which are highest among various iron oxide-GO/RGO composite adsorbents reported to date. Meanwhile, $\mathrm{FeO}_{\mathrm{x}}-\mathrm{GO}-80$ has been demonstrated to remarkably reduce the arsenic concentration from 118 (for As(III)) or $108 \mu \mathrm{g} \mathrm{L}^{-1}$ (for As(V)) to $<0.02 \mu \mathrm{g} \mathrm{L}^{-1}$. The kinetic study also confirms the fast uptake of arsenic with $\mathrm{FeO}_{\mathrm{x}}-\mathrm{GO}-80$. The $\mathrm{pH}$ study indicates that $\mathrm{As}(\mathrm{V})$ is adsorbed through electrostatic interactions while $\mathrm{As}(\mathrm{III})$ is adsorbed by surface complexation. In addition, $\mathrm{FeO}_{\mathrm{x}}-\mathrm{GO}-80$ shows well-retained adsorption performance towards $\mathrm{As}(\mathrm{III})$ despite the excessive presence of co-existing anions $\left(\mathrm{SO}_{4}{ }^{2-}, \mathrm{CO}_{3}{ }^{2-}\right.$, and $\left.\mathrm{PO}_{4}{ }^{3-}\right)$. With the superior performance, this class of $\mathrm{FeO}_{\mathrm{x}}-\mathrm{GO}$ nanocomposites has high potential for arsenic removal in practical water treatment, particularly in drinking water purification, given the low cost of GO that can be produced cost-effectively from abundant natural graphite and the convenient synthesis of the nanocomposites. Further mechanistic studies 
and the evaluation on the reusability of the nanocomposites and their suitability in column studies are to be undertaken.

\section{Supporting Information Available}

AFM image of GO (Figure S1); $\mathrm{C} 1 \mathrm{~s}$ and $\mathrm{O} 12$ XPS spectra of GO, $\mathrm{FeO}_{\mathrm{x}}-\mathrm{GO}-36, \mathrm{FeO}_{\mathrm{x}}-\mathrm{GO}-80$ and the iron oxide control sample (Figure S2); particle size distribution of the $\mathrm{Fe}_{3} \mathrm{O}_{4}$ nanoparticles in the iron oxide control sample (Figure S3); DF-STEM image and elemental maps of $\mathrm{FeO}_{\mathrm{x}}-\mathrm{GO}-80$ and $\mathrm{FeO}_{\mathrm{x}}-\mathrm{GO}-36$ (Figures $\mathrm{S} 4$ and S5); Raman spectra (Figure S6); arsenic adsorption uptake with $\mathrm{FeO}_{\mathrm{x}}-\mathrm{GO}-80$ at different dosages (Figure S7); summary of fitting parameters of arsenic adsorption isotherms and kinetics (Tables S1 and S2).

\section{Acknowledgement}

We thank the Natural Science and Engineering Research Council (NSERC) of Canada for funding this research through an Engage Grant (EGP 491823-15) and a Discovery Grant (RGPIN-2015-03815).

\section{References}

[1] B.K. Mandal, K.T. Suzuki, Arsenic round the world: a review, Talanta 58 (2002) 201-235.

[2] P.L. Smedley, D.G. Kinniburgh, A review of the source, behavior and distribution of arsenic in natural waters, Appl. Geochem. 17 (2002) 517-568.

[3] T.S.Y. Choong, T.G. Chuah, Y. Robiah, F.L.G. Koay, I. Azni, Arsenic toxicity, health hazards and removal techniques from water: an overview, Desalination 217 (2007) 139-166. 
[4] D. Mohan, C.U. Pittman Jr, Arsenic removal from water/wastewater using adsorbents - a critical review, J. Hazard. Mater. 142 (2007) 1-53.

[5] S.C.N. Tang, I.M.C. Lo, Magnetic nanoparticles: essential factors for sustainable environmental applications, Water Res. 47 (2013) 2613-2632.

[6] M.L. Pierce, C.B. Moore, Adsorption of arsenite and arsenate on amorphous iron hydroxide, Water Res. 16 (1982) 1247-1253.

[7] K.P. Raven, A. Jain, R.H. Loeppert, Arsenite and arsenate adsorption on ferrihydrite: kinetics, equilibrium and adsorption envelopes, Environ. Sci. Technol. 32 (1998) 344-349.

[8] S. Dixit, J.G. Hering, Comparison of arsenic(V) and arsenic(III) sorption onto iron oxide minerals: implications for arsenic mobility, Environ. Sci. Technol. 37 (2003) 4182-4189.

[9] S. Luther, N. Borgfeld, J. Kim, J.G. Parsons, Removal of arsenic from aqueous solution: a study of the effects of $\mathrm{pH}$ and interfering ions using iron oxide nanomaterials, Microchem. J. $101(2012) 30-36$.

[10] S. Yean, L. Cong, C.T. Yavuz, J.T. Mayo, W.W. Yu, A.T. Kan, V.L. Colvin, M.B. Tomson, Effect of magnetite particle size on adsorption and desorption of arsenite and arsenate, J. Mater. Res. 20 (2005) 3255-3264.

[11]C.T. Yavuz, J.T. Mayo, W.W. Yu, A. Prakash, J.C. Falkner, S. Yean, L. Cong, H.J. Shipley, A. Kan, M. Tomson, D. Natelson, V.L. Colvin, Low-field magnetic separation of monodisperse $\mathrm{Fe}_{3} \mathrm{O}_{4}$ nanocrystals, Science 314 (2006) 964-967.

[12] T. Tuutijärvi, J. Lu, M. Sillanpää, G. Chen, As(V) adsorption on maghemite nanoparticles, J. Hazard. Mater. 166 (2009) 1415-1420.

[13]L.-S. Zhong, J.-S. Hu, H.-P. Liang, A.-M. Cao, W.-G. Song, L.-J. Wan, Self-assembled 3D flowerlike iron oxide nanostructures and their application in water treatment, Adv. Mater. 18 (2006) 2426-2431. 
[14]F. Mou, J. Guan, Z. Xiao, Z. Sun, W. Shi, X.-A. Fan, Solvent-mediated synthesis of magnetic $\mathrm{Fe}_{2} \mathrm{O}_{3}$ chestnut-like amorphous-core/ $\gamma$-phase-shell hierarchical nanostructures with strong As(V) removal capability, J. Mater. Chem. 21 (2011) 5414-5421.

[15]F. Mou, J. Guan, H. Ma, L. Xu, W. Shi, Magnetic iron oxide chestnutlike hierarchical nanostructures: preparation and their excellent arsenic removal capabilities, ACS Appl. Mater. Interfaces 4 (2012) 3987-3993.

[16]C.-Y. Cao, J. Qu, W.-S. Yan, J.-F. Zhu, Z.-Y. Wu, W.-G. Song, Low-cost synthesis of flowerlike $\alpha-\mathrm{Fe}_{2} \mathrm{O}_{3}$ nanostructures for heavy metal ion removal: adsorption property and mechanism, Langmuir 28 (2012) 4573-4579.

[17]B. Wang, H. Wu, L. Yu, R. Xu, T.-T. Lim, X.W. Lou, Template-free formation of uniform urchin-like $\alpha-\mathrm{FeOOH}$ hollow spheres with superior capability for water treatment, Adv. Mater. 24 (2012) 1111-1116.

[18]T. Wang, L. Zhang, H. Wang, W. Yang, Y. Fu, W. Zhou, W. Yu, K. Xiang, Z. Su, S. Dai, L. Chai, Controllable synthesis of hierarchical porous $\mathrm{Fe}_{3} \mathrm{O}_{4}$ particles mediated by poly(diallyldimethylammonium chloride) and their application in arsenic removal, ACS Appl. Mater. Interfaces 5 (2013) 12449-12459.

[19]Z. Wei, R. Xing, X. Zhang, S. Liu, H. Yu, P. Li, Facile template-free fabrication of hollow nestlike $\alpha-\mathrm{Fe}_{2} \mathrm{O}_{3}$ nanostructures for water treatment, ACS Appl. Mater. Interfaces 5 (2013) $598-604$.

[20] G.K. Das, C.S. Bonifacio, J. De Rojas, K. Liu, K. van Benthem, I.M. Kennedy, Ultra-long magnetic nanochains for highly efficient arsenic removal from water, J. Mater. Chem. A. 2 (2014) 12974-12981.

[21] M. Jang, S.-H. Min, T.-H. Kim, J.K. Park, Removal of arsenite and arsenate using hydrous ferric oxide incorporated into naturally occurring porous diatomite, Environ. Sci. Technol. 40 (2006) 1636-1643. 
[22]Z. Gu, J. Fang, B. Deng, Preparation and evaluation of GAC-based iron-containing adsorbents for arsenic removal, Environ. Sci. Technol. 39 (2005) 3833-3843.

[23] V. Chandra, J. Park, Y. Chun, J.W. Lee, I.-C. Hwang, K.S. Kim, Water-dispersible magnetite-reduced graphene oxide composites for arsenic removal, ACS Nano 4 (2010) 3979-3986.

[24]K. Zhang, V. Dwivedi, C. Chi, J. Wu, Graphene oxide/ferric hydroxide composites for efficient arsenate removal from drinking water, J. Hazard. Mater. 182 (2010) 162-169.

[25]X.-L. Wu, L. Wang, C.-L. Chen, A.-W. Xu, X.-K. Wang, Water-dispersible magnetitegraphene-LDH composites for efficient arsenate removal, J. Mater. Chem. 21 (2011) 1735317359.

[26] G. Sheng, Y. Li, X. Yang, X. Ren, S. Yang, J. Hu, X. Wang, Efficient removal of arsenate by versatile magnetic graphene oxide composites, RSC Adv. 2 (2012) 12400-12407.

[27]J. Zhu, R. Sadu, S. Wei, D.H. Chen, N. Haldolaarachchige, Z. Luo, J.A. Gomes, D.P. Young, Z. Guo, Magnetic graphene nanoplatelet composites toward arsenic removal, ECS J. Solid State Sci. Techn. 1 (2012) M1-M5.

[28] J. Zhu, S. Wei, H. Gu, S.B. Rapole, Q. Wang, Z. Luo, N. Haldolaarachchige, D.P. Young, Z. Guo, One-pot synthesis of magnetic graphene nanocomposites decorated with core@doubleshell nanoparticles for fast chromium removal, Environ. Sci. Technol. 46 (2012) 977-985.

[29]Y. Wang, Q. He, H. Qu, X. Zhang, J. Guo, J. Zhu, G. Zhao, H.A. Colorado, J. Yu, L. Sun, S. Bhana, M.A. Khan, X. Huang, D.P. Young, H. Wang, X. Wang, S. Wei, Z. Guo, Magnetic graphene oxide nanocomposites: nanoparticles growth mechanism and property analysis, J. Mater. Chem. C 2 (2014) 9478-9488.

[30] G. Gollavelli, C.-C. Chang, Y.-C. Ling, Facile synthesis of smart magnetic graphene for safe drinking water: heavy metal removal and disinfection control, ACS Sustainable Chem. Eng. 1 (2013) 462-472. 
[31]B. Paul, V. Parashar, A. Mishra, Graphene in the $\mathrm{Fe}_{3} \mathrm{O}_{4}$ nano-composite switching the negative influence of humic acid coating into an enhancing effect in the removal of arsenic from water, Environ. Sci.: Water Res. Technol. 1 (2015) 77-83.

[32]F. Yu, S. Sun, J. Ma, S. Han, Enhanced removal performance of arsenate and arsenite by magnetic graphene oxide with high iron oxide loading, Phys. Chem. Chem. Phys. 17 (2015) $4388-4397$.

[33]J. Ding, B. Li, Y. Liu, X. Yan, S. Zeng, X. Zhang, L. Hou, Q. Cai, J. Zhang, Fabrication of $\mathrm{Fe}_{3} \mathrm{O}_{4} @$ reduced graphene oxide composite via novel colloid electrostatic self-assembly process for removal of contaminants from water, J. Mater. Chem. A 3 (2015) 832-839.

[34]X. Yu, S. Tong, M. Ge, J. Zuo, C. Cao, W. Song, One-step synthesis of magnetic composites of cellulose@iron oxide nanoparticles for arsenic removal, J. Mater. Chem. A 1 (2013) 959965.

[35]Z. Wu, W. Li, P.A. Webley, D. Zhao, General and controllable synthesis of novel mesoporous magnetic iron oxide@carbon encapsulates for efficient arsenic removal, Adv. Mater. 24 (2012) 485-491.

[36]M. Baikousi, A.B. Bourlinos, A. Douvalis, T. Bakas, D.F. Anagnostopoulos, J. Tucek, K. Safarova, R. Zboril, M.A. Karakassides, Synthesis and characterization of $\gamma-\mathrm{Fe}_{2} \mathrm{O}_{3} /$ carbon hybrids and their application in removal of hexavalent chromium ions from aqueous solutions, Langmuir 28 (2012) 3918-3930.

[37]B. Chen, Z. Zhu, J. Ma, Y. Qiu, J. Chen, Surfactant-assisted Ce-Fe mixed oxide decorated multiwalled carbon nanotubes and their arsenic adsorption performance, J. Mater. Chem. A $1(2013) 11355-11367$.

[38]J. Yang, H. Zhang, M. Yu, I. Emmanuelawati, J. Zou, Z. Yuan, C. Yu, High-content, welldispersed $\gamma-\mathrm{Fe}_{2} \mathrm{O}_{3}$ nanoparticles encapsulated in macroporous silica with superior arsenic removal performance, Adv. Funct. Mater. 24 (2014) 1354-1363. 
[39]H. Chang, H. Wu, Graphene-based nanocomposites: preparation, functionalization, and energy and environmental applications, Energy Environ. Sci. 6 (2013) 3483-3507.

[40]J. Zhu, M. Chen, Q. He, L. Shao, S. Wei, Z. Guo, An overview of the engineered graphene nanostructures and nanocomposites, RSC Adv. 3 (2013) 22790-22824.

[41]K.C. Kemp, H. Seema, M. Saleh, N.H. Le, K. Mahesh, V. Chandra, K.S. Kim, Environmental applications using graphene composites: water remediation and gas adsorption, Nanoscale 5 (2013) 3149-3171.

[42]R.K. Upadhyay, N. Soin, S.S. Roy, Role of graphene/metal oxide composites as photocatalysts, adsorbents and disinfectants in water treatment: a review, RSC Adv. 4 (2014) 3823-3851.

[43]D.C. Marcano, D.V. Kosynkin, J.M. Berlin, A. Sinitskii, Z. Sun, A. Slesarev, L.B. Alemany, W. Lu, J.M. Tour, Improved synthesis of graphene oxide, ACS Nano 4 (2010) 4806-4814.

[44] W.S. Hummers, R.E. Offeman, Preparation of graphitic oxide, J. Am. Chem. Soc. 80 (1958) 1339.

[45]C.P. Huang, L.M. Vane, Enhancing $\mathrm{As}^{5+}$ removal by a $\mathrm{Fe}^{2+}$-treated activated carbon, J. Water Pollut. Control Fed. 61 (1989) 1596-1603.

[46] S. Stankovich, D.A. Dikin, R.D. Piner, K.A. Kohlhaas, A. Kleinhammes, Y. Jia, Y. Wu, S.T. Nguyen, R.S. Ruoff, Synthesis of graphene-based nanosheets via chemical reduction of exfoliated graphite oxide, Carbon 45 (2007) 1558-1565.

[47] W. Zhang, X. Shi, Y. Zhang, W. Gu, B. Li, Y. Xian, Synthesis of water-soluble magnetic graphene nanocomposites for recyclable removal of heavy metal ions, J. Mater. Chem. A 1 (2013) 1745-1753.

[48] S. Park, J. An, I. Jung, R.D. Piner, S.J. An, X. Li, A. Velamakanni, R.S. Ruoff, Colloidal suspension of highly reduced graphene oxide in a wide variety of organic solvents, Nano Lett. 9 (2009) 1593-1597. 
[49]H. Kong, J. Song, J. Jang, One-step fabrication of magnetic $\gamma-\mathrm{Fe}_{2} \mathrm{O}_{3} /$ polyrhodanine nanoparticles using in situ chemical oxidation polymerization and their antibacterial properties, Chem. Commun. 46 (2010) 6735-6737.

[50]G. Bhargava, I. Gouzman, C.M. Chun, T.A. Ramanarayanan, S.L. Bernasek, Characterization of the "native" surface thin film on pure polycrystalline iron: a high resolution XPS and TEM study, Appl. Surface Sci. 253 (2007) 4322-4329.

[51] S. Bera, M. Ghosh, M. Pal, N. Das, S. Saha, S. K. Dutta, S. Jana, Synthesis, characterization and cytotoxicity of europium incorporated $\mathrm{ZnO}$-graphene nanocomposites on human MCF7 breast cancer cells. RSC Adv. 4 (2014) 37479-37490.

[52]L. Xu, J.-W. McGraw, F. Gao, M. Grundy, Z. Ye, Z. Gu, J.L. Shepherd, production of highconcentration graphene dispersions in low-boiling-point organic solvents by liquid-phase noncovalent exfoliation of graphite with a hyperbranched polyethylene and formation of graphene/ethylene copolymer composites, J. Phys. Chem. C 117 (2013) 10730-10742.

[53]K.S.W. Sing, D.H. Everett, R.A.W. Haul, L. Moscou, R.A. Pierotti, J. Rouquerol, T. Siemieniewska, Reporting physisorption data for gas/solid systems with special reference to the determination of surface area and porosity, Pure Appl. Chem. 57 (1985) 603-619.

[54] World Health Organization, Guidelines for Drinking Water Quality 2011.

[55]Y.S. Ho, G. Mckay, The kinetics of sorption of divalent metal ions onto sphagnum moss peat, Water Res. 34 (2000) 735-742. 
Supporting Information for

\title{
High-Performance Iron Oxide-Graphene Oxide Nanocomposite Adsorbents for Arsenic Removal
}

\author{
Hui Su, ${ }^{1}$ Zhibin $\mathrm{Ye}^{1, *}$ and Nuri Hmidi ${ }^{2}$
}

1 Bharti School of Engineering, Laurentian University, Sudbury, Ontario P3E 2C6, Canada

3 Goldcorp Incorporated, Red Lake Gold Mines, 15 Mine Road, Box 2000, Balmertown, Ontario P0V 1C0, Canada

* Corresponding author. Email: zye@laurentian.ca; Telephone: 1 (705) 6751151 ext. 2343 

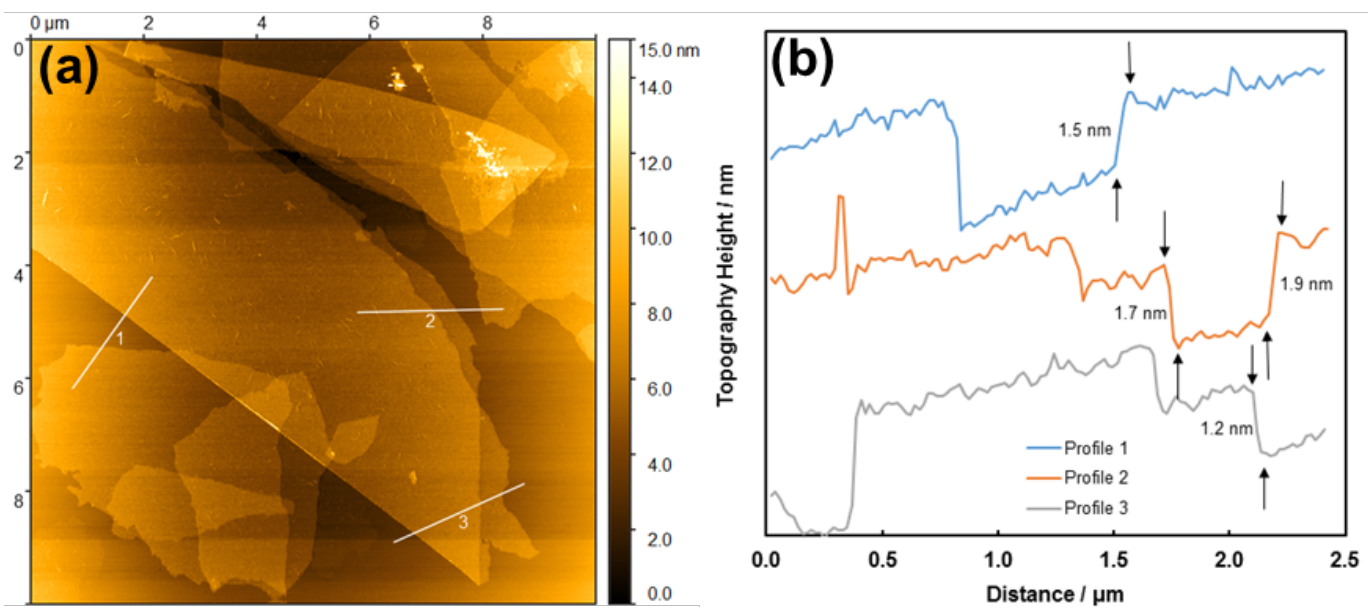

Figure S1 (a) AFM height image of GO; (b) height profiles across three profiles denoted in (a). 

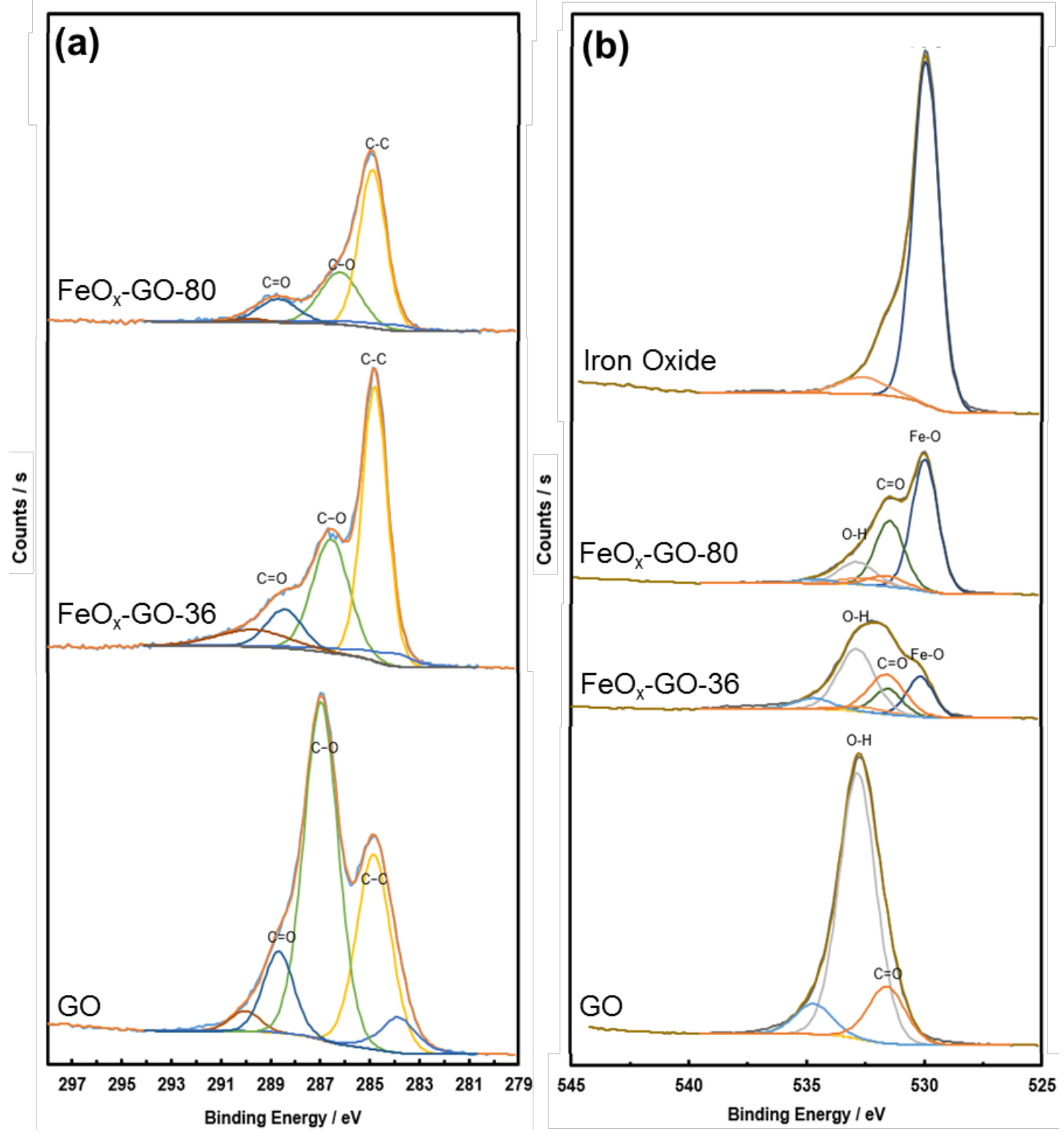

Figure S2. The $\mathrm{C}_{1 \mathrm{~s}}$ (a) and $\mathrm{O}_{1 \mathrm{~s}}(\mathrm{~b})$ scan results of $\mathrm{GO}, \mathrm{FeO}_{\mathrm{x}}-\mathrm{GO}-36, \mathrm{FeO}_{\mathrm{x}}-\mathrm{GO}-80$ and the iron oxide control sample. 


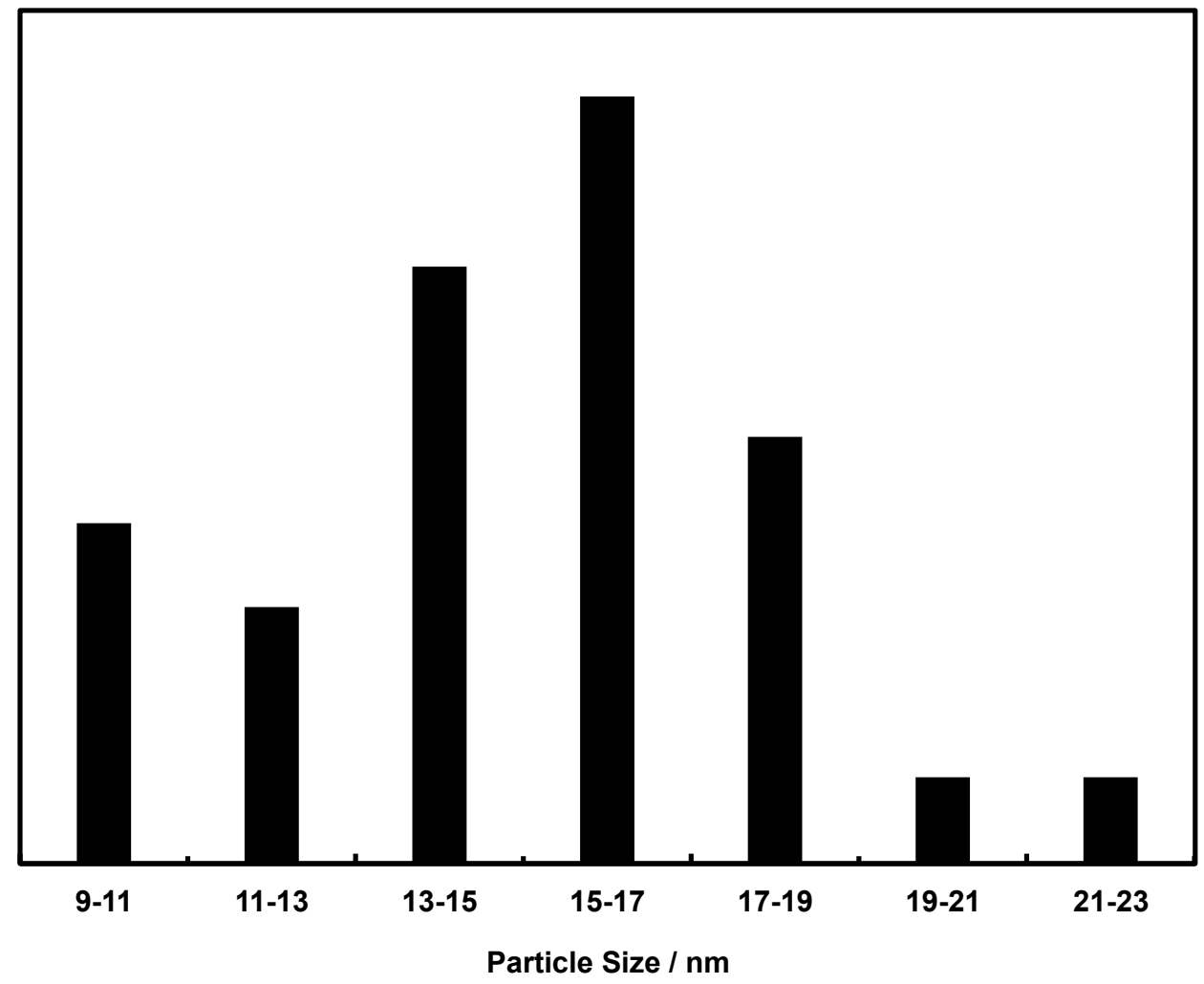

Figure S3. Particle size distribution of the $\mathrm{Fe}_{3} \mathrm{O}_{4}$ nanoparticles (on the basis of 120 nanoparticles found in TEM) in the iron oxide control sample. 


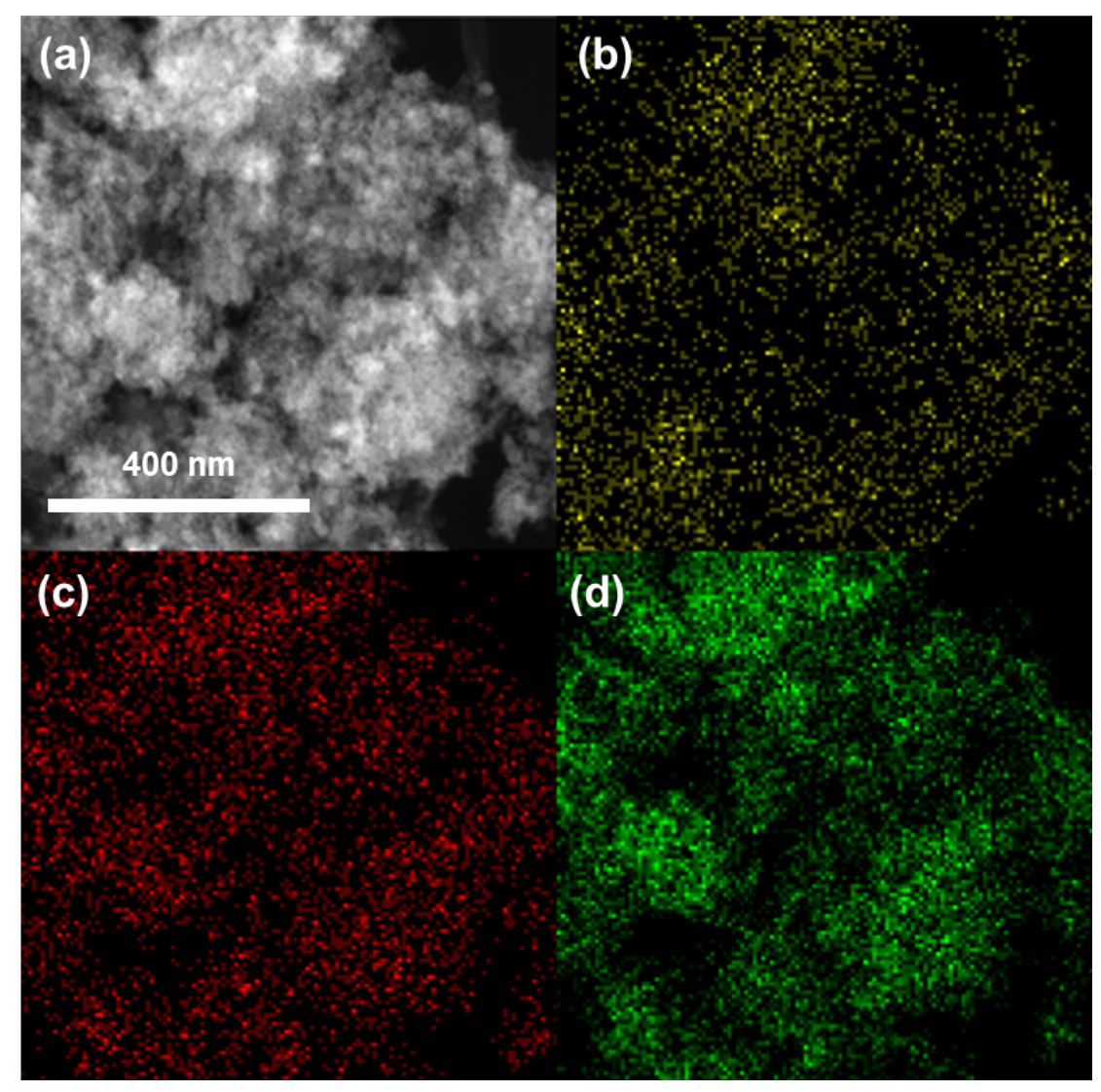

Figure S4. DF-STEM image (a) and the corresponding C (b), O (c), and Fe (d) elemental maps of $\mathrm{FeO}_{\mathrm{x}}-\mathrm{GO}-80$. 


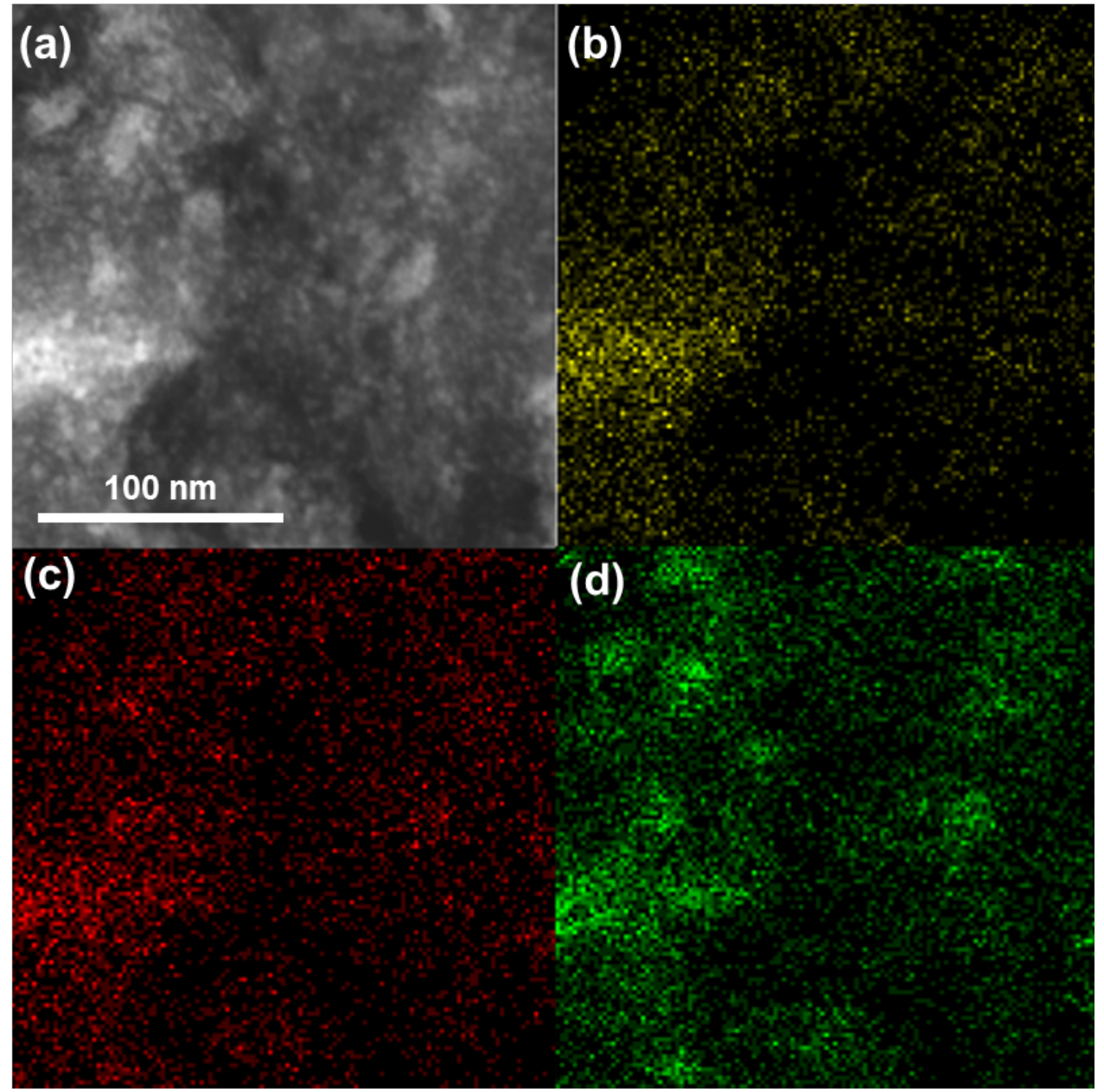

Figure S5. DF-STEM image (a) and the corresponding C (b) O (c) and Fe (d) elemental maps of $\mathrm{FeO}_{\mathrm{x}}-\mathrm{GO}-36$. 

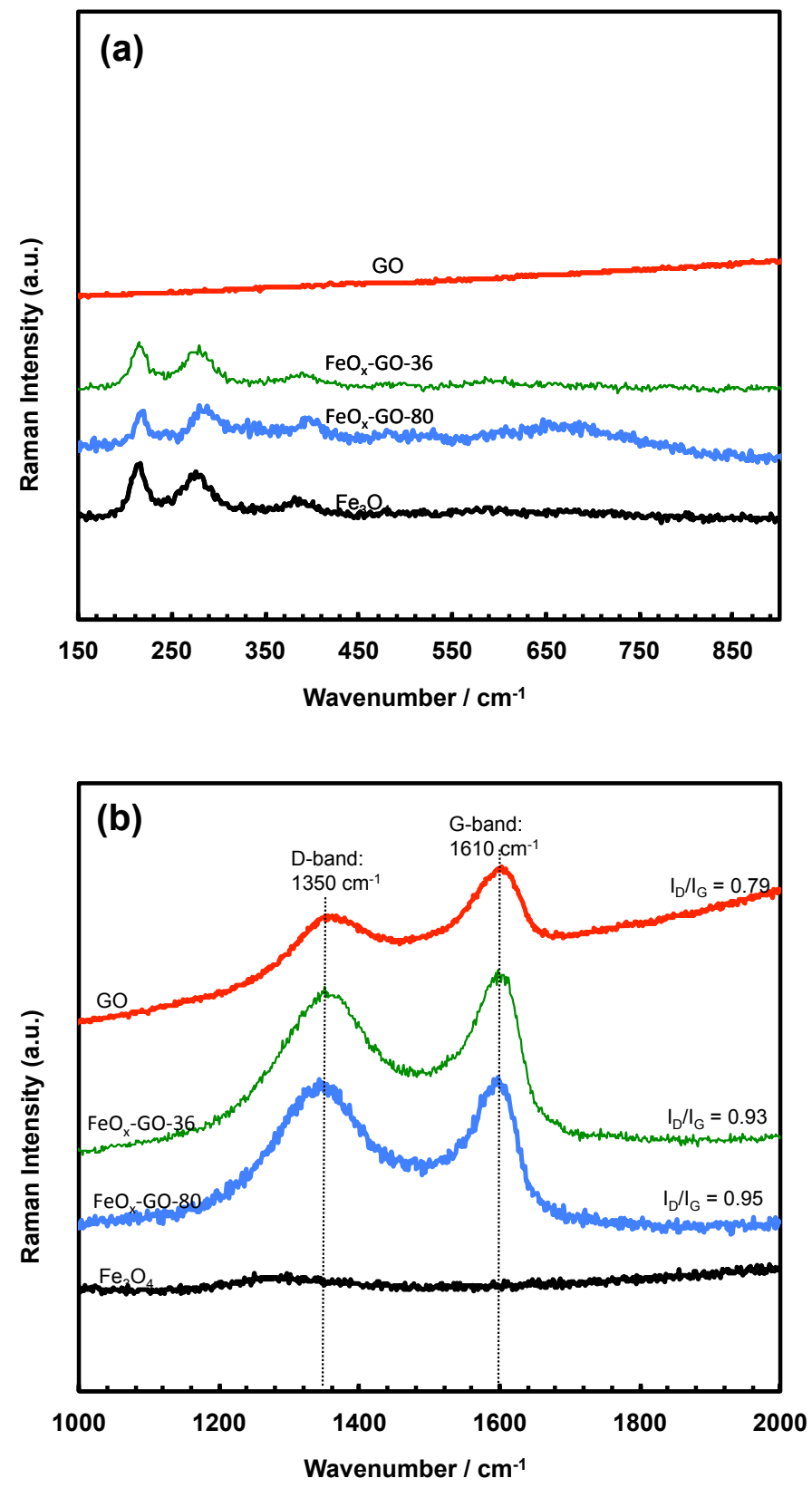

Figure S6. Raman spectra of $\mathrm{GO}, \mathrm{FeO}_{\mathrm{x}}-\mathrm{GO}-36, \mathrm{FeO}_{\mathrm{x}}-\mathrm{GO}-80$, and the $\mathrm{Fe}_{3} \mathrm{O}_{4}$ control sample. 


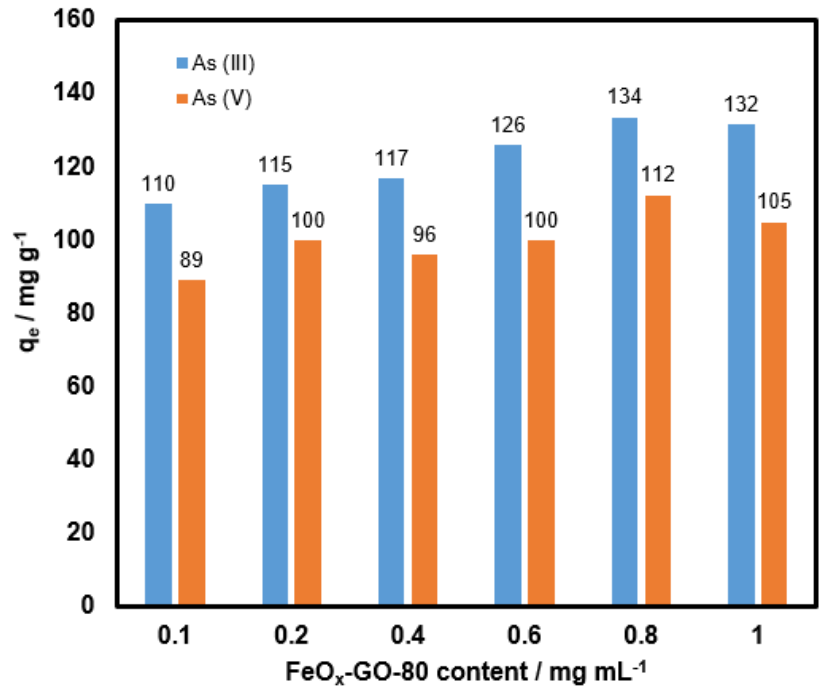

Figure S7. Arsenic adsorption with $\mathrm{FeO}_{\mathrm{x}}-\mathrm{GO}-80$ at different dosages $\left(0.1-1 \mathrm{mg} \mathrm{mL}^{-1}\right)$. Initial arsenic concentration: 1200 and $350 \mathrm{mg} \mathrm{L}^{-1}$ for $\mathrm{As}(\mathrm{III})($ at $\mathrm{pH}=7$ ) and $\mathrm{As}(\mathrm{V})($ at $\mathrm{pH}=3$ ), respectively. 

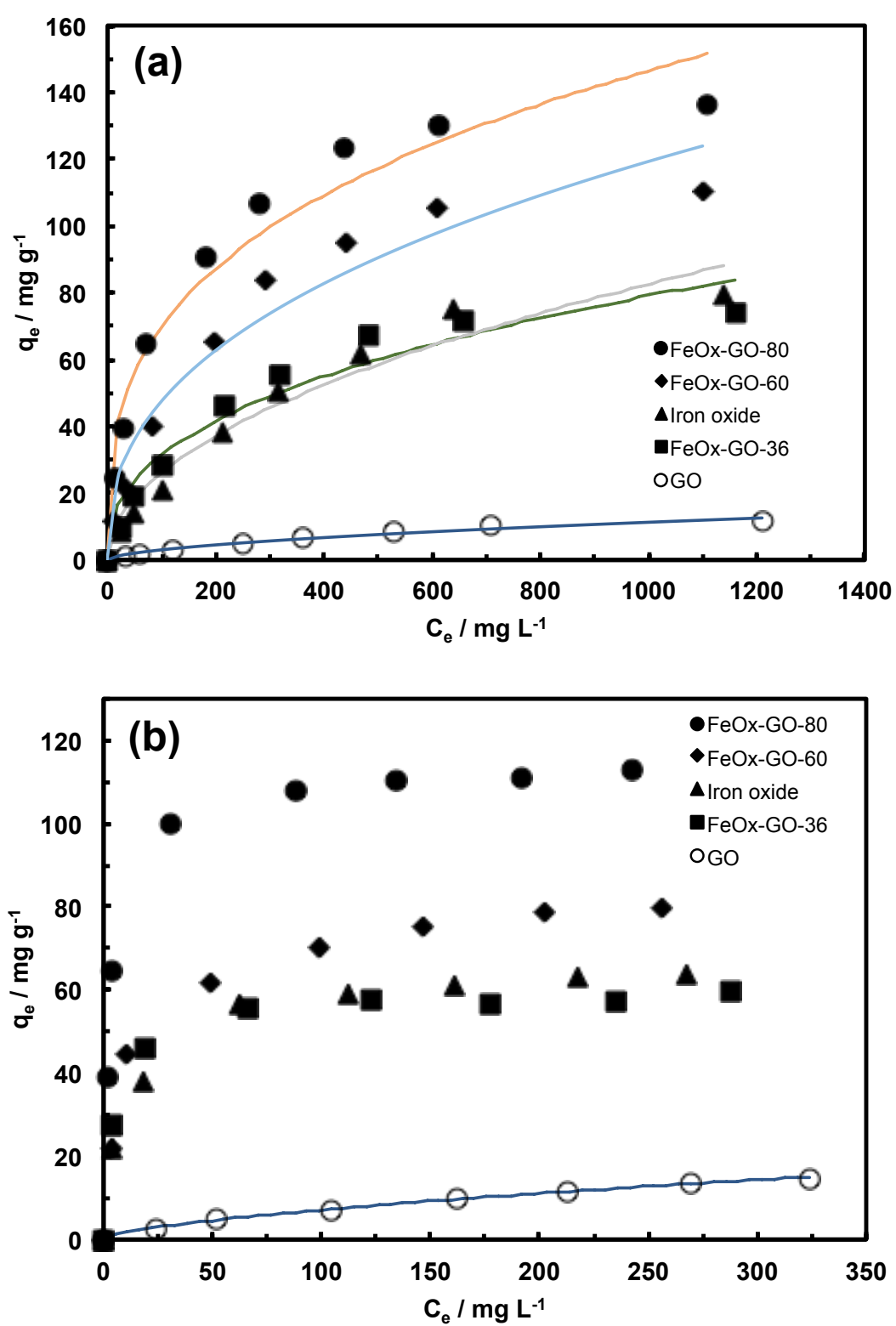

Figure S8. Freundlich fitting of the isotherms of (a) As(III) adsorption and (b) As(V) adsorption. In the case of $\mathrm{As}(\mathrm{V})$ adsorption isotherms in (b), no fitting can be made except that of GO. 
Table S1. A summary of the fitting parameters of arsenic adsorption isotherms and kinetics with $\mathrm{FeO}_{\mathrm{x}}-\mathrm{GOs}$, GO, and the iron oxide control sample.

\begin{tabular}{|c|c|c|c|c|c|c|c|}
\hline Samples & \multicolumn{3}{|c|}{ Langmuir model } & \multicolumn{4}{|c|}{ Pseudo-second-order kinetic model } \\
\hline $\mathrm{As}(\mathrm{III})$ & $\mathrm{R}^{2}$ & $\begin{array}{c}\mathrm{q}_{\max } \\
\left(\mathrm{mg} \mathrm{g}^{-1}\right)\end{array}$ & $\begin{array}{c}\mathrm{b} \\
\left(\mathrm{L} \mathrm{mg}^{-1}\right)\end{array}$ & $\mathrm{R}^{2}$ & $\begin{array}{c}\mathrm{k}_{2} \\
\left(\mathrm{~g} \mathrm{mg}^{-1} \min ^{-1}\right)\end{array}$ & $\begin{array}{c}\mathrm{V}_{0} \\
\left(\mathrm{mg} \mathrm{g}^{-1} \min ^{-1}\right)\end{array}$ & $\begin{array}{c}\mathrm{q}_{\mathrm{eq}} \\
\left(\mathrm{mg} \mathrm{g}^{-1}\right)\end{array}$ \\
\hline GO & 0.983 & 19 & 0.001 & & & & \\
\hline $\mathrm{FeO}_{\mathrm{x}}-\mathrm{GO}-36$ & 0.993 & 90 & 0.005 & & & & \\
\hline $\mathrm{FeO}_{\mathrm{x}}-\mathrm{GO}-60$ & 0.994 & 132 & 0.005 & & & & \\
\hline $\mathrm{FeO}_{\mathrm{x}}-\mathrm{GO}-80$ & 0.991 & 147 & 0.011 & 1.000 & 0.001 & 11.3 & 110 \\
\hline Iron oxide & 0.987 & 110 & 0.003 & & & & \\
\hline Samples & \multicolumn{3}{|c|}{ Langmuir model } & \multicolumn{4}{|c|}{ Pseudo-second-order kinetic model } \\
\hline $\operatorname{As}(V)$ & $\mathrm{R}^{2}$ & $\begin{array}{c}\mathrm{q}_{\max } \\
\left(\mathrm{mg} \mathrm{g}^{-1}\right)\end{array}$ & $\begin{array}{c}\mathrm{b} \\
\left(\mathrm{L} \mathrm{mg}^{-1}\right)\end{array}$ & $\mathrm{R}^{2}$ & $\begin{array}{c}\mathrm{k}_{2} \\
\left(\mathrm{~g} \mathrm{mg}^{-1} \min ^{-1}\right)\end{array}$ & $\begin{array}{c}\mathrm{V}_{0} \\
\left(\mathrm{mg} \mathrm{g}^{-1} \min ^{-1}\right)\end{array}$ & $\begin{array}{c}\mathrm{q}_{\mathrm{eq}} \\
\left(\mathrm{mg} \mathrm{g}^{-1}\right)\end{array}$ \\
\hline GO & 0.989 & 28 & 0.003 & & & & \\
\hline $\mathrm{FeO}_{\mathrm{x}}-\mathrm{GO}-36$ & 0.991 & 59 & 0.208 & & & & \\
\hline $\mathrm{FeO}_{\mathrm{x}}-\mathrm{GO}-60$ & 0.981 & 80 & 0.098 & & & & \\
\hline $\mathrm{FeO}_{\mathrm{x}}-\mathrm{GO}-80$ & 0.994 & 113 & 0.295 & 1.000 & 0.001 & 7.4 & 114 \\
\hline Iron oxide & 0.981 & 65 & 0.097 & & & & \\
\hline
\end{tabular}


Table S2. A summary of the Freundlich fitting of arsenic adsorption isotherms with $\mathrm{FeO}_{\mathrm{x}}-\mathrm{GOs}$, GO, and the iron oxide control sample.

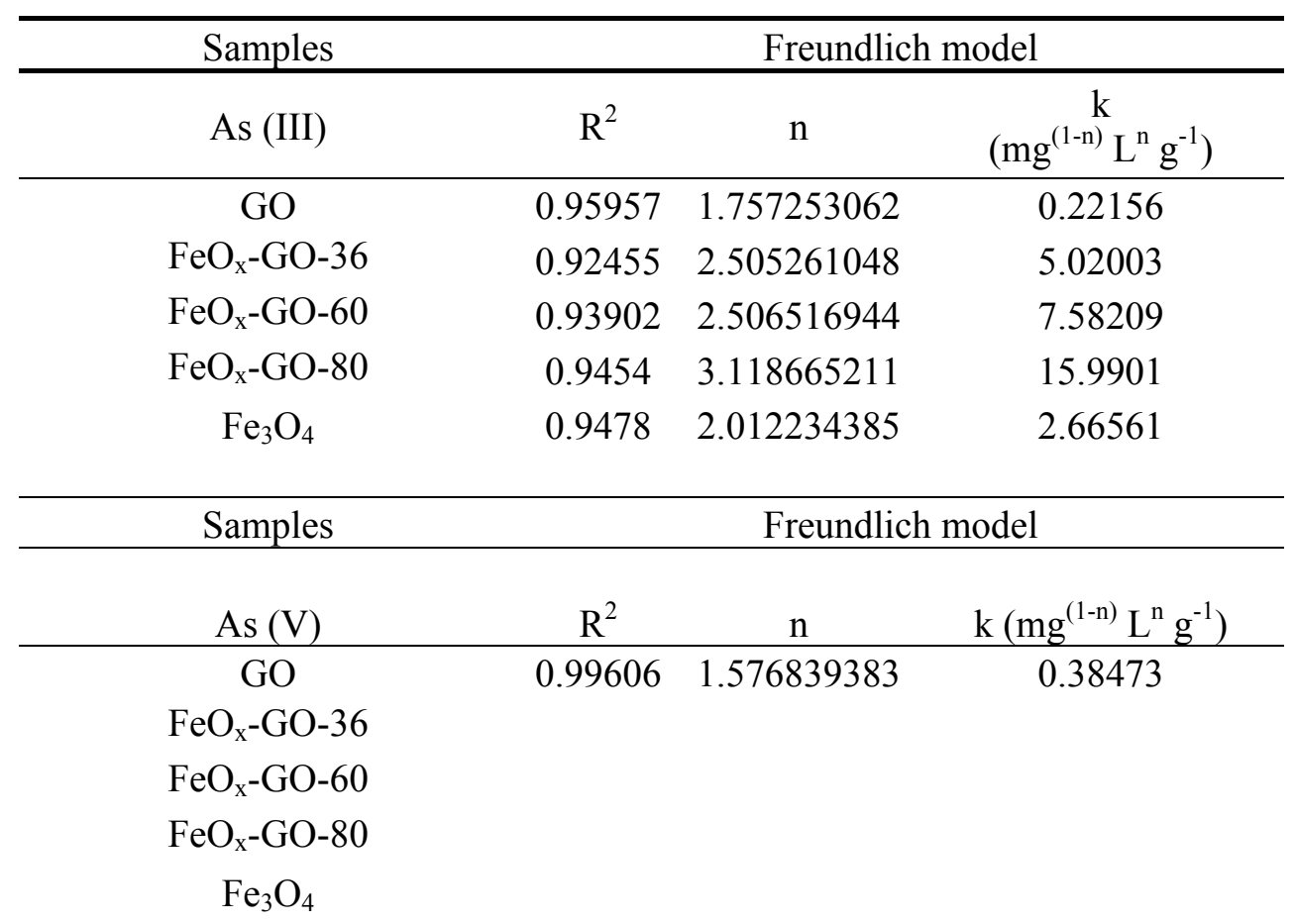

